NBER WORKING PAPER SERIES

DETERMINANTS OF NEONATAL MORTALITY

RATES IN THE U.S.: A REDUCED FORM MODEL

Hope Corman

Michael Grossman

Working Paper No. 1387

NATIONAL BUREAU OF ECONOMIC RESEARCH

1050 Massachusetts Avenue

Cambridge, MA 02138

June 1984

The research reported here is part of the NBER's research program in Health Economics. Any opinions expressed are those of the authors and not those of the National Bureau of Economic Research or the National Institute of Child Health and Human Development which funded the project. 
Determinants of Neonatal Mortality Rates in the U.S.: A Reduced Form Model

\begin{abstract}
The aim of this paper is to contribute to an understanding of the determinants of differences in race-specific neonatal mortality rates among large counties of the U.S. in 1977. After estimating cross-sectional regressions, we apply their coefficients to national trends in the exogenous variables to "explain" the rapid decline in neonatal mortality since 1964. The regressions and the extrapolations point to the importance of abortion availability, neonatal intensive care availability, females schooling levels, and to a lesser extent Medicaid, BCHS projects, and WIC in trends in black neonatal mortality between 1964 and 1977. They also underscore the importance of schooling, neonatal intensive care, abortion, Medicaid, WIC, and to a lesser extent poverty and organized family planning clinics in trends in white neonatal mortality in those years. A particularly striking finding is that the increase in abortion availability is the single most important factor in the reduction in the black neonatal mortality rate. Not only does the growth in abortion dominate other program measures, but it also dominates trends in schooling, poverty, female employment, and physician availability. The actual reduction due to abortion amounts to 1.2 deaths per thousand live births or 10 percent of the observed decline.
\end{abstract}

Hope Corman Department of Economics Manhattan College Riverdale, New York 10471 (212) 920-0468

\author{
Michael Grossman \\ Department of Economics \\ City University of New York \\ Graduate School \\ 33 W. 42nd Street \\ New York, New York 10036 \\ (212) 790-4411
}


DETERMINANTS OF NEONATAL MORTALITY RATES IN THE U.S.:

A REDUCED FORM MODEL

Hope Corman and Michael Grossman*

During the period from 1955 through 1982, the behavior of the U.S. infant mortality rate has been characterized by a decade of relative stability followed by almost two decades of rapid decline. The rate declined by only 0.6 percent per year compounded annually between 1955 and 1964 . By contrast, infant mortality declined 4.5 percent per year (compounded annually) between 1964 and 1982. ${ }^{1}$

The trend in the infant mortality rate since 1964 has been dominated by the trend in the neonatal mortality rate (deaths of infants within the first 27 days of life) for two reasons. First, the neonatal mortality rate, 8.9 deaths per thousand live births in 1979, is twice as large as the postneonatal mortality rate (deaths of infants between the ages of 28 and 364 days per thousand live births), which equaled to 4.2 in 1979. Second, the neonatal mortality rate has fallen at a faster pace than the postneonatal mortality rate since 1964 (4.6 percent per year versus 3.9 percent per year). The result of these two factors is that the decline in the neonatal mortality rate accounted for 77 percent of the reduction in the infant mortality rate during the past two decades. It follows that any attempt to explain the recent behavior of infant mortality must focus on neonatal mortality.

The period beginning in 1964 witnessed the introduction of Medicaid, maternal and infant care ( $M$ and $I$ ) projects, community health centers 
(CHCs, formerly called neighborhood health centers), Federally subsidized family planning services for low-income women, the Special Supplemental Food Program for Women, Infants, and Children (WIC program), the legalization of abortion, the widespread adoption of oral and intrauterine contraceptive techniques, and dramatic advances in perinatal ${ }^{2}$ and neonatal science. Although other researchers have related these developments to accelerations in the downward trends in infant and especially neonatal mortality rates (for example, Eisner et al. 1978; Kleinman et al. 1978; Lee et a1. 1980; David and Siegal 1983), there have been few attempts to study this issue in a multivariate context. Moreover, there has been only one previous effort to quantify the relative contributions of at least some of these factors (Grossman and Jacobowitz 1981). Therefore, the aim of this paper is to contribute to an understanding of the determinants of neonatal mortality rates in the U.S. with an emphasis on the factors just mentioned. Estimates of their effects control for such basic correlates of neonatal mortality as poverty, schooling levels, and the availability of obstetricians/ gynecologists.

The aim is implemented by conducting cross-sectional regression analyses of differences in race-specific neonatal mortality rates among counties of the U.S. in 1977. This procedure capitalizes on variations in the public program at issue and in units that deliver sophisticated perinatal and neonatal care services among counties at a moment in time. After estimating the regressions, we apply their coefficients to national trends in the exogenous variables to "explain" the downward trend in neonatal mortality. 


\section{Analytical Framework}

Economic models of the family developed by Becker and Lewis (1973) and Willis (1973) provide a fruitful theoretical framework to generate multivariate health outcome functions and to assess the roles of a variety of factors in these functions. Ben-Porath and Welch (1976), Williams (1976), Grossman and Jacobowitz (1981), Rosenzweig and Schu1tz (1982, 1983a, 1983b), and Lewit (1983) have utilized the economic model of the family to study theoretically and empirically the determinants of birth outcomes. Following these authors, we assume that the parents' utility function depends on their own consumption, the number of births, and the survival probability. Both the number of births and the survival probability are endogenous variables. In particular, the survival probability production function depends upon such endogenous inputs as the quantity and quality of medical care, nutrition, and the own time of the mother. In addition, the production function is affected by the reproductive efficiency of the mother and by other aspects of her efficiency in household production. Given the considerable body of evidence that education raises market and nonmarket productivity, one would expect more educated mothers to be more efficient producers of surviving infants.

Maximization of the parents' utility function subject to production and resource constraints generates a demand function for survival in which the survival probability is related to input prices, efficiency, income, tastes, and the fixed costs of a birth. Fixed costs are costs that are independent of the survival probability. For example, Willis (1973) shows that birth control costs are negatively correlated with the fixed costs of a birth. A reduction in the cost of fertility control raises the fixed 
cost of a birth, reduces the optimal number of births, and raises the optimal survival probability. The interaction between the survival demand and production functions determines demand functions for medical care and other endogenous inputs. These derived demand functions depend on the same set of variables as the demand function for the probability of survival.

The above model calls attention to the important determinants of the survival probability and its complement, the neonatal mortality rate. In general this set of determinants is similar to that used in multivariate studies of neonatal mortality with different points of departure (for example, Fuchs 1974; Williams 1974; Brooks 1978, Gortmaker 1979; Hadley 1982; Harris 1982). Moreover, the model provides a ready structure within which to interpret the impacts of the factors at issue in our research. ${ }^{3}$ Thus, for example, Medicaid, M and I projects, and community health centers lower the direct and indirect $\operatorname{costs}^{4}$ of obtaining medical care, which should increase the likelihood of a favorable birth outcome and lower neonatal mortality. Similar comments apply to the impacts of increases in the availability of physicians who deliver prenatal and perinatal care services and to the number of hospitals with perinatal and neonatal intensive care units, which provide constant and continuous care to critically ill newborn infants. An expansion in the percentage of eligible pregnant women served by the WIC program raises the availability of appropriate nutrition, an important nonmedical input in the production of healthy infants. Subsidization of family planning services and the diffusion and availability of abortion services reduce the costs of fertility control. Within the context of an economic model of the family, these developments raise the "optimal" survival probability and lower the "optimal" number of 
births. In addition, they will lower the observed infant mortality rate if less healthy fetuses are less likely to be conceived or more likely to be aborted.

The preceding ideas are formalized in the following six equation model:

$$
\begin{aligned}
1-\mathrm{d} & =\mathrm{f}_{1}(\mathrm{n}, \mathrm{b}) \\
\mathrm{b} & =\mathrm{f}_{2}(\mathrm{~m}, \mathrm{a}, \mathrm{c}, \mathrm{z}) \\
\mathrm{n} & =\mathrm{f}_{3}(\mathrm{p}, \mathrm{z}, \mathrm{y}) \\
\mathrm{m} & =\mathrm{f}_{4}(\mathrm{p}, \mathrm{z}, \mathrm{y}) \\
\mathrm{a} & =\mathrm{f}_{5}(\mathrm{p}, \mathrm{z}, \mathrm{y}) \\
\mathrm{c} & =\mathrm{f}_{6}(\mathrm{p}, \mathrm{z}, \mathrm{y}) .
\end{aligned}
$$

Equations (1) and (2) are production functions, while equations (3)-(6) are input demand functions. In equation (1) the probability that an infant survives the first month of life ( $1-d$, where $d$ is the probability of death) is shown as a function of a vector of perinatal and neonatal care inputs (n) and birth weight (b). ${ }^{5}$ Note that there is an overwhelming amount of evidence that low birth weight (less than or equal to 2,500 grams or 5.5 pounds) is the most important and most proximate endogenous risk factor in neonatal health outcomes (for example, Harris 1982; Lewit 1983). In equation (2) birth weight is a function of a vector of prenatal medical and nonmedical inputs $(m),{ }^{6}$ the use of abortion services (a), the use of contraceptive services (c), and exogenous risk and productive efficiency factors such as mother's education ( $z)$. In equations (3)-(6), the inputs are related to a vector of price and availability measures ( $p)$, socioeconomic characteristics which reflect command over resources and tastes $(y)$, and productive efficiency and risk factors ( $z$ ). 
The two production functions are structural equations because they show relationships among endogenous variables. Substitution of the input demand functions into the production functions yields

$$
\begin{aligned}
1-\mathrm{d} & =\mathrm{f}_{7}(\mathrm{p}, \mathrm{z}, \mathrm{y}) \\
\mathrm{b} & =\mathrm{f}_{8}(\mathrm{p}, \mathrm{z}, \mathrm{y})
\end{aligned}
$$

These are reduced form equations because only exogenous variables appear on their right-hand sides. They may be termed demand functions for survival and birth weight. Together with the input demand functions, they constitute the reduced form of the model. ${ }^{7}$ Although equations (1)-( 8 ) have meaningful interpretations at the family level, our empirical analysis focuses on county-level data for the year 1977. Therefore, from now on we interpret $d$ as the observed neonatal mortality rate and $b$ as the percentage of low-birth weight births.

We focus on the estimation of the reduced form neonatal mortality rate equation (7) because its coefficients are well suited for understanding the impacts of changes in policy variables and for extrapolating, crosssectional regression results to national trends in exogenous variables to "explain" the decline in neonatal mortality. 8 Since the reduced form mortality function contains only exogenous variables, it can be fitted by ordinary least squares. 9

Our model calls attention to the difference between the availability and the use of services such as family planning, abortion, prenatal care, perinatal care, and neonatal care, all of which determine birth outcomes. An increase in the availability of an input lowers its price and causes the quantity demanded of that input to rise but has an ambiguous effect on the 
demand for some other input. For example, an increase in the availability of abortion services may reduce the use of family planning services if these methods of fertility control are substitutes. Thus, an increase in the availability of one service can affect neonatal mortality both directly and indirectly, through its effect on the use of other services. By focusing on availability rather than use, we can capture both direct and indirect effects of changes in the availability of medical services on neonatal mortality.

\section{Empirical Specification}

\section{A. Data and Measurement of Neonatal Mortality}

The basic data set used here is the Area Resource File (ARF), a countybased data service, prepared by Applied Management Sciences, Inc., for the Bureau of Health Professions, U.S. Department of Health and Human Services. It incorporates information from different sources for the 3,077 counties of the United States. Neonatal deaths by race for the years 1969 through 1978 are obtained from the National Center for Health Statistics (NCHS) Mortality Tape. Births by race for those years are obtained from the NCHS Natality Tape. Health Manpower comes from the American Medical Association. Socioeconomic characteristics are taken from the Census of Population. We have added measures pertaining to the policies and programs discussed previously from sources indicated in the Appendix to this paper (available upon request).

For reasons mentioned in the introductory section, the empirical analysis focuses on the neonatal mortality rate as opposed to the postneonatal mortality rate or the total infant death rate. Also, this strategy is 
adopted because most neonatal deaths are caused by congenital anomalies, prematurity, and complications of delivery. These conditions are more sensitive to improved prenatal, perinatal, and neonatal care than are the infectious diseases and accidents that contribute to postneonatal mortality. Neonatal mortality may be particularly sensitive to abortion and organized family planning access, since women at risk of conditions causing neontal mortality can be identified during pregnancy and encouraged to use appropriate birth control methods in the future.

Separate regressions are fitted for white neonatal mortality and for black neonatal mortality. Black neonatal mortality rates are much higher than white rates. For example, in 1977 the black rate was almost twice as large as the white rate. In a non-race-specific regression, one would enter the percentage of black births to control for race differences. But this variable would be highly correlated with the percentage of low-income women, schooling, and other independent variables. By fitting racespecific regressions, multicollinearity is reduced and the coefficients of the independent variables are allowed to vary between races. Linear regressions are estimated for reasons indicated in section II.B.

Counties are our units of observation rather than Standard Metropolitan Statistical Areas (SMSAs) because counties are more homogeneous with respect to key variables such as income, schooling, medical resources, and others. Some counties are so small, however, that people may receive medical care outside the county. Also, small counties, with few births, experience large fluctuations in birth rates simply due to random movements. The problems with county data are reduced by including only counties with a population of at least 50,000 persons in 1970 . A county must 
also have at least 5,000 blacks for inclusion in the black regressions. There are 677 counties in the white regressions and 357 counties in the black regressions. ${ }^{10}$ The counties used in the white regressions accounted for approximately 80 percent of the white population of the U.S. in 1970, and the counties used in the black regressions accounted for a similiar percentage of the black population of the U.S. in that year. In addition to selecting large counties, we attenuate random elements by employing a three-year average of the race-specific neonatal mortality rate for the period 1976-1978 as the dependent variable and by estimating weighted regressions, where the set of weights is the square root of the racespecific total number of births in the period 1976-1978.

Neonatal mortality for a three-year period centered on 1977 is studied to address the question: Do the effects that Grossman and Jacobowitz (1981) observed in 1971, particularly the large negative abortion effect, differ when data for 1977 are examined? Our approach also differs from theirs because we focus on a reduced form neonatal mortality rate equation, and we include many more determinants of neonatal mortality. For example, we are now able to measure the contribution of the rapid advances in perinatal and neonatal science since $1965 .^{11}$ These developments were accompanied by an approximately fourteen-fold increase in the number of hospitals with neonatal (defined to include perinatal) intensive care units between 1964 and 1977 (Sheridan 1983). Note that although the state-of-the-art in neonatology is fixed in the cross section, the availability of these state-of-theart services varies considerably from one geographic area to another due to regional differences in hospital construction subsidies (by states and the Federal government), Medicaid reimbursement, Federal funding of neonatal 
intensive care centers (under Title $V$ of the Social Security Act), state certificate-of-need laws and regionalization of neonatal intensive care programs.

In fact, all variables in the cross section vary considerably even though technology and the legal environment are fixed. Our abortion variable, for example, had a coefficient of variation of 77 percent, even though abortion had been legalized in all states by 1973 .

\section{B. Measurement of Independent Variables}

Wherever possible, race-specific variables are employed in the regressions. Such variables are denoted with an asterisk. Except for the Medicaid, WIC, and neonatal intensive care measures, all variables are county-specific. Table 1 contains definitions and acronyms of the dependent and independent variables in the regressions, and Table 2 contains their means and standard deviations. Most of the independent variables pertain to one or more years in the 1975-1978 period. Several measures pertain to $1970,1979,1980$, or 1981 . In these cases the assumption is made that the 1975-1978 measure is highly correlated with the one actually used. A detailed description of the variables and their sources appears in the Appendix (available upon request), which also contains a discussion of preliminary regression results obtained with several additional independent variables that are not shown in Section III.

The percentage of women aged 15 to 44 with family income less than 200 percent of the poverty level in 1980 (POV*) is a negative correlate of command over resources and is expected to have a positive regression coefficient. As explained in Section I, the percentage of women aged 15 to 49 
TABLE 1

Definitions of Variables ${ }^{a}$

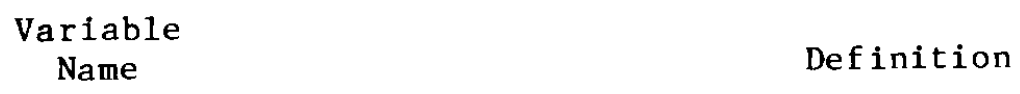

NMR7 7*

Three-year average neonatal mortality rate centered on 1977; deaths of infants less than 28 days old per 1,000 1 ive births

povk ${ }^{b}$

HSP* ${ }^{c}$

$\operatorname{EMP} \star^{C}$

OBG

POBG

MPA $^{\mathrm{d}}$

$M P U^{d}$

MPN $^{\mathrm{d}}$

MNEW

MBEN
Percentage of women aged 15-44 with family income less than 200 percent of the poverty level in 1980

Percentage of women aged 15-49 who had at least a high school education in 1970

Percentage of women aged 15-49 employed in 1970

Number of non-federal obstetricians/gynecologists in patient care in 1975 per 1,000 women aged 15-44 in 1975

Percentage of non-federal board-certified obstetricians/ gynecologists in 1975

Dichotomous variable that equals one if county is in state that covered all first-time pregnancies under Medicaid to financially eligible women in the period $1976-1978$

Dichotomous variable that equals one if county is in state that covered first-time pregnancies under Medicaid only if no husband was present or if the husband was present but unemployed and not receiving unemployment compensation in the period 1976-1978

Dichotomous variable that equals one if county is in state that covered first-time pregnancies under Medicaid only if no husband was present in the period 1976-1978

Dichotomous variable that equals one if county is in state in which Medicaid paid for newborn care under the mother's Medicaid number or did not pay for care under the mother's number but allowed pregnant women to register their "unborn children" with Medicaid in 1981

St ate-specific average annual Medicaid payment per adult recipient in AFDC families in fiscal 1976 
TABLE 1 (concluded)

Variable

Name Definition

FPCLINP ${ }^{\mathrm{e}}$

$\mathrm{BCHSP}^{\mathrm{e}}$

WIC

ABPROV

$\mathrm{NEOH}$

NMR7 0*
Number of organized family planning clinics in 1975 per 1,000 women aged $15-44$ with family income less than 200 percent of the poverty level in 1975

Sum of maternal and infant care ( $M$ and $I$ ) projects and community health centers ( $\mathrm{CHCs}$ ) in 1976 per 1,000 women aged 15-44 with family income less than 200 percent of the poverty level in 1975; numerator termed Bureau of Community Health Services (BCHS) projects

State-specific percentage of eligible pregnant women served by the Special Supplemental Food Program for Women, Infants, and Children (WIC program) in 1980

Three-year average number of abortion providers centered on 1976 per 1,000 women aged 15-44 in 1975

Sum of state-specific number of hospitals with Level II, or Level III, or Levels II and III neonatal intensive care units in 1979 per 1,000 women aged 15-44 in state in 1975

Th ree-year average neonatal mortality rate centered on 1970

aAn asterisk (*) next to a variable means that it is race-specific.

bVariable is available for nonblacks and blacks as opposed to whites and blacks.

cVariable is available for whites and nonwhites as opposed to whites and blacks.


time pregnant women for prenatal care under Medicaid. The omitted category pertains to states that cover no first-time pregnancies because their AFDC programs do not recognize "unborn children."

esince nume rator of this variable is not race-specific, denominator also is not race-specific. Denominator is obtained by applying the racespecific percentage of women aged 15-44 with family income less than 200 percent of the poverty level in 1980 to the race-specific number of all women aged 15-44 in 1975. 
TABLE 2

Means and Standard Deviations of Dependent and Independent Variables ${ }^{\text {a }}$

\begin{tabular}{|c|c|c|c|c|}
\hline \multirow[b]{2}{*}{ Variable } & \multicolumn{2}{|c|}{ Whites } & \multicolumn{2}{|c|}{ Blacks } \\
\hline & Me an & $\begin{array}{l}\text { Standard } \\
\text { Deviation }\end{array}$ & Mean & $\begin{array}{l}\text { Standard } \\
\text { Deviation }\end{array}$ \\
\hline \multicolumn{5}{|c|}{ Mode1 1} \\
\hline NMR7 7* & 8.837 & 1.596 & 16.387 & 3.303 \\
\hline NMR7 0* & 13.336 & 1.940 & 22.496 & 4.018 \\
\hline HSP* & 62.830 & 7.306 & 44.120 & 8.968 \\
\hline POV* & 26.617 & 8.779 & 54.896 & 9.371 \\
\hline EMP* & 43.591 & 5.280 & 47.188 & 6.359 \\
\hline OBG & .446 & .222 & .585 & .293 \\
\hline POBG & 57.156 & 19.755 & 54.706 & 14.224 \\
\hline $\mathrm{NEOH}$ & .011 & .004 & .010 & .003 \\
\hline ABPROV & .056 & .043 & .056 & .036 \\
\hline FPCLINP & .271 & .190 & .271 & .209 \\
\hline B CHSP & .018 & .035 & .025 & .032 \\
\hline WIC & 26.289 & 7.804 & 26.793 & 7.419 \\
\hline MPA & .388 & .488 & .265 & .442 \\
\hline MPU & .137 & .344 & .106 & .309 \\
\hline MPN & .087 & .282 & .166 & .373 \\
\hline MNEW & .927 & .260 & .943 & .232 \\
\hline MBEN & 453.266 & 142.016 & 448.560 & 137.223 \\
\hline
\end{tabular}

\section{$\underline{\text { Additional Mode1 } 2 \text { Variables }}{ }^{\text {b }}$}

FPCL INPXPOV*
BCHSPXPOV*
WICXPOV*
MPAXPOV*
MPUXPOV*
MPNXPOV*
MNEWX POV*
MBENXPOV*

FPCL INPXPOV* BCHSPXPOV*

MPAXPOV* MPUXPOV* MNEWX POV* MBENXPOV*

$\begin{array}{rr}.149 & .128 \\ .014 & .019 \\ 14.782 & 5.133 \\ .139 & .235 \\ .054 & .159 \\ .102 & .230 \\ .520 & .157 \\ 241.201 & 70.450\end{array}$

The white data pertain to 677 counties, while the black data pertain to 357 counties. Means and standard deviations are weighted by the racespecific total number of births in the period 1976-1978.

bIn the formation of Model 2 variables, POV* is multiplied by .01. 
who had at least a high school education in 1970 (HSP*) is a proxy for reproductive efficiency and other aspects of efficiency in household production. The schooling variable also may serve as a proxy for the parents' preferences for healthy offspring. Whether schooling represents efficiency, tastes, or both, the neonatal mortality rate should be negatively related to it. ${ }^{12}$ Employed women have a higher opportunity cost of time than other women, but they also may have higher income. Therefore, the net effect of an increase in the percentage of women aged 15 to 49 who were employed in 1970 (EMP*) on the neonatal mortality rate is indeterminant. 13 The number of non-federal obstetricians/gynecologists in patient care in 1975 per thousand women aged 15 to 44 in 1975 (OBG) and the percentage of such physicians who are board certified ( $P O B G$ ) are general indexes of the availability of medical care to pregnant women and of the availability of high-quality care.

The key public program measures at issue in this paper pertain to Medicaid, organized family planning clinics, maternal and infant care projects, community health centers, WIC, abortion availability, and neonatal care availability. A11 of the measures are expected to have negative regression coefficients. The eligibility of low-income women who are pregnant for the first time for Medicaid coverage of their prenatal care services is reflected by three dichotomous variables (MPN, MPU, and MPA). MPN equals one for counties in states that covered first-time pregnancies only if no husband was present in the period 1976-1978. MPU equals one for counties in states that provided coverage if no husband was present or if the husband was present but unemployed and not receiving unemployment insurance. MPA equals one for counties in states that provided coverage to 
all financially eligible women, regardless of the presence or employment status of the husband. The omitted category pertains to counties in states that covered no first-time pregnancies because their aid to families with dependent children (AFDC) programs did not recognize "unborn children." The likelihood that the newborn care received by the infant of a low-income woman will be financed by Medicaid is indicated by a dichotomous variable (MNEW) that equals one if a county is in a state in which Medicaid paid for newborn care under the mother's Medicaid number or did not pay for care under the mother's number but allowed pregnant women to register their unborn children with Medicaid in 1981.

There are no data on differences in the availability of Medicaid coverage of prenatal care for second- and higher-order births or on differences in the general availability of physicians to Medicaid-eligible women among states or counties. Therefore, the state-specific average annual Medicaid payment per adult recipient in AFDC families in fiscal 1976 (MBEN) is included as a regressor. Although this variable partly reflects the use of care, it also reflects price and availability. This is because physicians in states with relatively low reimbursement schedules under Medicaid are less likely to treat Medicaid patients (Sloan, Mitchell, and Cromwell 1978).

Organized family planning availability is given by the number of organized family planning clinics in 1975 per thousand women aged 15 to 44 with family income less than 200 percent of the poverty level in 1975 (FPCLINP). The denominator pertains to poor women because the clinics primarily service poor women and because the relevant public program is aimed at the poor. 
Dryfoos (1976) reports that almost all clients of family planning clinics use oral or intrauterine contraceptive techniques (the pill or the IUD). Consequently, the family planning variable indicates the price and availability of these techniques to low-income women. There are no direct measures of the availability of family planning services delivered by private physicians to poor or nonpoor women. Therefore, the obstetrician/ gynecologist variable reflects the availability of private family planning services as well as prenatal and perinatal care services. There is no information concerning differences in contraceptive knowledge among counties. It is likely, however, that more educated women will have better birth control information. Thus, the schooling variable may partly reflect this factor.

The extent of the maternal and infant care program and the community health center program is given by the sum of $M$ and I projects and CHCs in 1976 per thousand women aged 15 to 44 with family income less than 200 percent of the poverty level in 1975 (BCHSP). The number of poor women serves as the denominator of this variable for the same reason that it serves as the denominator of the family planning measure. $M$ and $I$ projects and CHCs are aggregated in the numerator because both provide prenatal care services to low-income women. ${ }^{14}$ The acronym of this variable pertains to the Bureau of Community Health Services (BCHS, renamed the Bureau of Health Care Delivery and Assistance in 1982), which is the agency within the U.S. Department of Health and Human Services that has overall administrative responsibility for both $M$ and $I$ projects and CHCs. The variable is referred to as BCHS project availability from now on. 
as of 1976 because the number of CHCs expanded rapidly between 1976 and 1978. Given Goldman and Grossman's (1982) evidence the CHCs affect infant mortality with a lag, the potential impacts of the new centers are not likely to be observed in our data. Note that the number of $M$ and $I$ projects was very stable between 1971 and 1978 (Grossman and Jacobowitz 1981).

The availability of nutritional supplements to low-income women under the WIC program is given by the state-specific percentage of eligible pregnant women served by WIC in 1980 (WIC). Abortion availability is measured as a three-year average of the number of abortion providers centered on 1976 per thousand women aged 15 to 44 in 1975 (ABPROV). Provider data for the years 1975, 1976, and 1977 are utilized because Grossman and Jacobowitz's (1981) estimates suggest that abortions performed in the first half of a given year affect the neonatality mortality rate during the second half of the year. Providers include public hospitals, private hospitals, nonhospital clinics, and office-based physicians. A provider must have performed at least one abortion in a given year to be included in the count in that year.

For part of our sample period (August 1977 through December 1978), Federal funding of abortions under Medicaid was banned by the Hyde Amendment except in cases where the woman's life was in danger. During that period, 28 states refused to pay for "medically necessary" abortions. The other 22 states continued to finance most abortions for Medicaideligible women. We do not take account of this curtailment in the availability of abortion to low-income women in our regression analysis because it could have impacted the neonatal mortality rate in 1978 alone. More importantly, Cates (1981) reports that an estimated 94 percent of pregnant 
low-income women "at risk" obtained a legal abortion between August 1977 and February 1980, 65 percent with state funds and 29 percent with other sources of funding. ${ }^{15}$ This suggests that abortion use by low-income women is very unresponsive to the money price of an abortion. It does not imply that abortion use is insensitive to such indirect costs as the time and money spent traveling to an abortion facility, the time spent waiting at the facility, and the time spent in obtaining information about alternative facilities. These indirect costs are likely to be very sensitive to the abortion availability measure used in the regression.

Neonatal intensive care availability is measured by the sum of the state-specific number of hospitals with Level II, Level III, or Levels II and III neonatal intensive care units in 1979 per thousand women aged 15 to 44 in the state in $1975(\mathrm{NEOH})$. Hospitals that provide neonatal intensive care are generally divided into three levels based on the intensity of care each is equipped to deliver. Level I hospitals provide minimal or normal newborn care; Level II hospitals provide intermediate care; and Level III hospitals provide the most intensive care (Budetti et al. 1981). Specific definitions of these three levels of neonatal care are contained in the recommendations of the Committee on Perinatal Health (1977), which were developed as guidelines for the regional development of perinatal health services.

In the estimation of the availability of neonatal intensive care, the state is used as the relevant market area rather than the county. This is because many states have developed formal or informal regional referral networks for $i l 1$ neonates. Under regionalization, it is possible for a newborn to be transferred out of his county of birth, suggesting that the 
market area for this care is larger than the county. This is in contrast to organized family planning, BCHS project, and abortion availability where regional networks do not exist. Moreover, the decision to obtain neonatal intensive care is made jointly by the physician and the mother, whereas the mother or the potential mother plays a much more important role in the decision to obtain the other services at issue. To the extent that the appropriate market area is larger than the country but smaller than the state, the neonatal intensive care variable contains measurement error. If the error is not correlated with the true value of the variable, the estimate of the avallability effect is biased toward zero.

Level I hospitals are excluded from the count of neocare hospitals since they do not provide the specialized state-of-the-art services in neonatology, referred to earlier. The count does not distinguish between Level II and Level III hospitals because of definitional problems in the available data.

The final variable in the regressions is a three-year average of racespecific neonatal mortality rate centered on 1970 (NMR70*). This variable is included to control for potential reverse causality relationships that may bias the coefficients of the program measures. For example, public programs such as BCHS projects and organized family planning clinics were targeted at regions with poor health indicators. For these programs, the availability of the program is positively related to the pre-program neonatal mortality rate. If the current and lagged mortality rates are positively related, then estimates of the impacts of these programs will be biased toward zero unless the initial level of mortality is included in the regression. For other public programs, avallability is negatively related 
to the pre-program neonatal mortality rate, causing the program coefficient to be overstated unless the lagged rate is included. For example, states that reformed their abortion laws by 1970 and enacted generous Medicaid programs tended to be liberal states with relatively large welfare programs and probably lower than average infant mortality rates. Thus, the dependence of program levels on the lagged mortality rate will cause a downward bias in the absolute value of a given program coefficient when the sign of the reverse causality relationship is positive and an upward bias in the absolute value of the coefficient when the sign of the reverse causality relationship is negative.

Ideally, we would like to include the lagged mortality rate for the period just prior to program inception. Since the current analysis includes so many programs, all beginning in different periods, this is clearly impossible. For programs established earlier, the 1970 lagged mortality rate does not allow for the full program effect to be captured in the measured coefficient since the program will have already reduced mortality by 1970 . That is, given serial correlation in both neonatal mortality rates and in program measures, this problem will tend to bias toward zero the coefficients of these program measures and possibly of other program measures ${ }^{16}$ when the 1970 lagged mortality rate is included. We call this the serial correlation bias. Due to the existence of both reverse causality bias and serial correlation bias, regressions are presented with and without the lagged neonatal mortality rate in Section III. ${ }^{17}$

A number of programs that we study are aimed at the poor. It follows that the impacts on neonatal mortality of such programs are larger the larger is the fraction of poor women. To be specific, let $d_{p j}$ be the 
neonatal mortality rate of babies born to poor mothers in the jth county, and let $d_{n j}$ be the neonatal mortality rate of babies born to nonpoor mothers. As an identity,

$$
d_{j}=k_{j} d_{p j}+\left(1-k_{j}\right) d_{n j},
$$

where $d_{j}$ is the observed neonatal mortality rate and $k_{j}$ is the fraction of births to poor mothers. Specify behavior equations for $d_{p j}, d_{n j}$, and $k_{j}$ as follows:

$$
\begin{aligned}
& d_{p j}=\alpha_{0}+\alpha_{1} x_{p j} \\
& d_{n j}=\beta_{0} \\
& k_{j}=\gamma_{0}+\gamma_{1} y_{j}+\gamma_{2} x_{p j}
\end{aligned}
$$

In these equations $x_{p j}$ is a public program availability measure that affects the mortality rate of poor babies alone and $y_{j}$ is the fraction of poor women in childbearing ages. Equation (11) contains the assumption that the mortality rate of nonpoor babies does not vary among counties, but this can be modified with little loss in generality. In equation (12) a program measure such as family planning availability is allowed to affect the function of births to poor women. Presumably, $\alpha_{1}$ and $\gamma_{2}$ are negative, ${ }^{18} \gamma_{1}$ is positive, and $\alpha_{0}$ exceeds $\beta_{0}$. Substitute equations (10), (11), and (12) into equation (9) to obtain

$$
\begin{aligned}
d_{j}= & \beta_{0}+\left(\alpha_{0}-\beta_{0}\right) \gamma_{0}+\left(\alpha_{0}-\beta_{0}\right) \gamma_{1} y_{j}+\left[\left(\alpha_{0}-\beta_{0}\right) \gamma_{2}+\alpha_{1} \gamma_{0}\right] x_{p j} \\
& +\alpha_{1} \gamma_{1} x_{p j} y_{j}+\alpha_{1} \gamma_{2} x_{p j}^{2}
\end{aligned}
$$


From equation (13) the effect of $\mathrm{x}_{\mathrm{pj}}$ on $\mathrm{d}_{j}$ is

$$
\left(\partial d_{j} / \partial x_{p j}\right)=\left(\alpha_{0}-\beta_{0}\right) \gamma_{2}+\alpha_{1} \gamma_{0}+\partial_{1} \gamma_{1} y_{j}+2 \alpha_{1} \gamma_{2} x_{p j},
$$

and this effect rises in absolute value as $y_{j}$ rises:

$$
\left(\partial^{2} d_{j} / \partial x_{p j} \partial y_{j}\right)=\alpha_{1} \gamma_{1} \cdot
$$

Equation (13) gives a multiple regression of $\mathrm{d}_{j}$ on $\mathrm{y}_{j}, \mathrm{x}_{\mathrm{pj}}$, $x_{p j} y_{j}$, and $x_{p j}^{2}$. With more than one public program measure, the regression has an extremely complicated functional form. Specifically, it includes the fraction of poor women, the level of each program measure, the square of that measure, its product with each of the other measures, and its product with the fraction of poor women. Such an equation is not tractable from the standpoint of estimation due to the large set of regressors and severe problems of multicollinearity. Therefore, two truncated versions of equation (13) are fitted in Section III. The first includes $y_{j}$ and $\mathrm{x}_{\mathrm{pj}}$ and is referred to as Model 1 . The second includes $\mathrm{y}_{j}$ and $\mathrm{x}_{\mathrm{pj}} \mathrm{y}_{j}$ and is referred to as Model 2. ${ }^{19}$ In the estimation of Mode1 2, the Medicaid, family planning, BCHS project, and WIC variables are interacted with the race-specific fraction of women aged 15 to 44 with family income less than 200 percent of the poverty level in 1980 (.01 POV*). The other variables are not interacted with the fraction of poor women because they reflect determinants of neonatal mortality that are relevant to the nonpoor as well as to the poor. The means and standard deviations of the eight interaction variables (FPCLINPXPOV*, BCHSPXPOV*, WICXPOV*, MPAXPOV*, MPUXPOV*, MPNXPOV*, MNEWXPOV*, and MBENXPOV*) are shown in the bottom part of Table 2. Linear 
regressions are estimated because a linear specification facilitates the aggregation of the two income-specific mortality functions [equations (11) and (12)] into a single equation for the entire population.

\section{Empirical Results}

Ordinary least squares regressions of white neonatal mortality rates in Mode1 1 (the non-interactive model) are contained in Panel A of Table 3, and ordinary least regressions of black neonatal mortality rates in Model 1 are contained in Panel $B$ of Table 3. The first regression in each panel (3-Al or 3-B1) excludes the lagged neonatal mortality rate, while the second regression (3-A2 or 3-B2) includes it. The corresponding Mode1 2 regressions (the interactive regressions) are shown in Panels $A$ and $B$ of Table 4 .

Based on the unadjusted coefficients of multiple determination $\left(R^{2} s\right)$, there is no clearcut evidence that one model is superior to the other. For both races, Mode1 2 outperforms Mode1 1 when the lagged neonatal mortality rate is a regressor. For whites, the reverse holds when the lagged neonatal mortality rate is omitted, while for blacks, the $\mathrm{R}^{2} \mathrm{~s}$ are identical in that specification. In all cases the differences between the $R^{2} \mathrm{~s}$ are small. Given the high degree of multicollinearity among regressors, these results are not surprising. Since Model 2 performs at least as well as Model 1 three times out of four and conceptually is somewhat more appropriate, the results in Table 4 are emphasized in the discussion of the signs and statistical significance of the coefficients below. Both models are, however, employed in the extrapolations. In general statements made 
TABLE 3

Ordinary Least Squares Regressions of Neonatal Mortality Rates, Mode1 $1^{\text {a }}$

\begin{tabular}{|c|c|c|c|c|c|c|c|c|}
\hline \multirow{3}{*}{$\begin{array}{c}\text { Independent } \\
\text { Variable }\end{array}$} & \multicolumn{4}{|c|}{ Pane1 A: Whites } & \multicolumn{4}{|c|}{ Pane1 B: B1 acks } \\
\hline & \multicolumn{4}{|c|}{ Regression Number } & \multicolumn{4}{|c|}{ Regression Number } \\
\hline & $\overline{(3-\mathrm{A} 1)}$ & $(3-A 2)$ & $(3-\mathrm{A} 3)$ & $(3-\mathrm{A} 4)$ & $(3-B 1)$ & $(3-B 2)$ & $(3-B 3)$ & $(3-B 4)$ \\
\hline NMR7 O* & -- & .283 & -- & .295 & $-\infty$ & .258 & -- & .275 \\
\hline & -- & $(9.30)$ & -- & $(9.47)$ & -- & $(6.09)$ & -- & $(6.44)$ \\
\hline HSP* & $\begin{array}{l}-.040 \\
(-3.97)\end{array}$ & $\begin{array}{l}-.025 \\
(-2.52)\end{array}$ & $\begin{array}{l}-.035 \\
(-3.40)\end{array}$ & $\begin{array}{l}-.018 \\
(-1.81)\end{array}$ & $\begin{array}{l}-.052 \\
(-1.52)\end{array}$ & $\begin{array}{l}-.012 \\
(-.38)\end{array}$ & $\begin{array}{c}-.047 \\
(-1.38)\end{array}$ & $\begin{array}{l}-.008 \\
(-.23)\end{array}$ \\
\hline POV* & $\begin{array}{l}.019 \\
(2.30)\end{array}$ & $\begin{array}{c}.013 \\
(1.57)\end{array}$ & $\begin{array}{c}.020 \\
(2.41)\end{array}$ & $\begin{array}{c}.012 \\
(1.58)\end{array}$ & $\begin{array}{l}-.016 \\
(-.51)\end{array}$ & $\begin{array}{l}-.009 \\
(-.29)\end{array}$ & $\begin{array}{l}.005 \\
(.17)\end{array}$ & $\begin{array}{l}.010 \\
(.32)\end{array}$ \\
\hline $\operatorname{EMP} *$ & $\begin{array}{l}.0006 \\
(.04)\end{array}$ & $\begin{array}{l}.006 \\
(.53)\end{array}$ & $\begin{array}{c}.022 \\
(1.79)\end{array}$ & $\begin{array}{l}.026 \\
(2.30)\end{array}$ & $\begin{array}{l}-.012 \\
(-.36)\end{array}$ & $\begin{array}{l}.002 \\
(.06)\end{array}$ & $\begin{array}{l}.015 \\
(.46)\end{array}$ & $\begin{array}{l}.024 \\
(.79)\end{array}$ \\
\hline OBG & $\begin{array}{l}1.856 \\
(6.32)\end{array}$ & $\begin{array}{l}1.714 \\
(6.19)\end{array}$ & -- & -- & $\begin{array}{l}2.757 \\
(4.08)\end{array}$ & $\begin{array}{l}2.306 \\
(3.56)\end{array}$ & -- & -- \\
\hline POBG & $\begin{array}{l}-.004 \\
(-1.35)\end{array}$ & $\begin{array}{l}-.001 \\
(-.47)\end{array}$ & $\begin{array}{l}-- \\
--\end{array}$ & $\begin{array}{l}-- \\
--\end{array}$ & $\begin{array}{l}.006 \\
(.50)\end{array}$ & $\begin{array}{l}.002 \\
(.21)\end{array}$ & -- & $\begin{array}{l}-- \\
--\end{array}$ \\
\hline $\mathrm{NEOH}$ & $\begin{array}{r}-32.360 \\
(-1.96)\end{array}$ & $\begin{array}{r}-28.462 \\
(-1.83)\end{array}$ & $\begin{array}{l}-48.460 \\
(-2.89)\end{array}$ & $\begin{array}{l}-43.212 \\
(-2.74)\end{array}$ & $\begin{array}{l}-95.486 \\
(-1.76)\end{array}$ & $\begin{array}{l}-64.916 \\
(-1.25)\end{array}$ & $\begin{array}{l}-96.961 \\
(-1.75)\end{array}$ & $\begin{array}{l}-64.495 \\
(-1.22)\end{array}$ \\
\hline ABPROV & $\begin{array}{l}-5.610 \\
(-3.45)\end{array}$ & $\begin{array}{l}-5.910 \\
(-3.86)\end{array}$ & $\begin{array}{l}-3.542 \\
(-2.17)\end{array}$ & $\begin{array}{l}-3.932 \\
(-2.57)\end{array}$ & $\begin{array}{r}-23.862 \\
(-3.92)\end{array}$ & $\begin{array}{r}-24.539 \\
(-4.24)\end{array}$ & $\begin{array}{r}-16.494 \\
(-2.78)\end{array}$ & $\begin{array}{r}-18.617 \\
(-3.32)\end{array}$ \\
\hline FPCL INP & $\begin{array}{l}-.561 \\
(-1.76)\end{array}$ & $\begin{array}{l}-.356 \\
(-1.18)\end{array}$ & $\begin{array}{c}-.642 \\
(-1.96)\end{array}$ & $\begin{array}{l}-.425 \\
(-1.38)\end{array}$ & $\begin{array}{l}-.656 \\
(-.75)\end{array}$ & $\begin{array}{l}-.044 \\
(-.05)\end{array}$ & $\begin{array}{l}-1.081 \\
(-1.22)\end{array}$ & $\begin{array}{l}-.361 \\
(-.43)\end{array}$ \\
\hline B CHSP & $\begin{array}{l}1.368 \\
(.792)\end{array}$ & $\begin{array}{l}.330 \\
(.20)\end{array}$ & $\begin{array}{l}3.236 \\
(1.85)\end{array}$ & $\begin{array}{l}2.008 \\
(1.22)\end{array}$ & $\begin{array}{r}-15.862 \\
(-2.76)\end{array}$ & $\begin{array}{r}-11.707 \\
(-2.13)\end{array}$ & $\begin{array}{r}-10.987 \\
(-1.93)\end{array}$ & $\begin{array}{l}-7.294 \\
(-1.34)\end{array}$ \\
\hline WIC & $\begin{array}{l}-.025 \\
(-3.02)\end{array}$ & $\begin{array}{l}-.012 \\
(-1.58)\end{array}$ & $\begin{array}{l}-.026 \\
(-3.01)\end{array}$ & $\begin{array}{l}-.012 \\
(-1.50)\end{array}$ & $\begin{array}{l}-.030 \\
(-1.14)\end{array}$ & $\begin{array}{r}-.0002 \\
(-.01)\end{array}$ & $\begin{array}{c}-.032 \\
(-1.21)\end{array}$ & $\begin{array}{r}-.0005 \\
(-.02)\end{array}$ \\
\hline MPA & $\begin{array}{l}-.384 \\
(-2.61)\end{array}$ & $\begin{array}{l}-.149 \\
(-1.06)\end{array}$ & $\begin{array}{c}-.417 \\
(-2.76)\end{array}$ & $\begin{array}{c}-.169 \\
(-1.17)\end{array}$ & $\begin{array}{l}-.332 \\
(-.66)\end{array}$ & $\begin{array}{l}-.304 \\
(-.63)\end{array}$ & $\begin{array}{l}-.284 \\
(-.55)\end{array}$ & $\begin{array}{l}-.252 \\
(-.52)\end{array}$ \\
\hline MPU & $\begin{array}{l}.067 \\
(.36)\end{array}$ & $\begin{array}{c}.209 \\
(1.17)\end{array}$ & $\begin{array}{l}.099 \\
(.51)\end{array}$ & $\begin{array}{l}.233 \\
(1.28)\end{array}$ & $\begin{array}{l}-.300 \\
(-.48)\end{array}$ & $\begin{array}{l}-.073 \\
(-.12)\end{array}$ & $\begin{array}{l}.241 \\
(.39)\end{array}$ & $\begin{array}{l}.405 \\
(.70)\end{array}$ \\
\hline MPN & $\begin{array}{l}.137 \\
(.60)\end{array}$ & $\begin{array}{l}.086 \\
(.40)\end{array}$ & $\begin{array}{l}.189 \\
(.81)\end{array}$ & $\begin{array}{l}.124 \\
(.56)\end{array}$ & $\begin{array}{l}-.317 \\
(-.55)\end{array}$ & $\begin{array}{l}.032 \\
(.06)\end{array}$ & $\begin{array}{l}-.267 \\
(-.45)\end{array}$ & $\begin{array}{l}.095 \\
(.17)\end{array}$ \\
\hline MNEW & $\begin{array}{l}-.086 \\
(-.36)\end{array}$ & $\begin{array}{l}-.013 \\
(-.06)\end{array}$ & $\begin{array}{l}-.042 \\
(-.17)\end{array}$ & $\begin{array}{l}.037 \\
(.16)\end{array}$ & $\begin{array}{c}-.915 \\
(-1.16)\end{array}$ & $\begin{array}{l}-.373 \\
(-.49)\end{array}$ & $\begin{array}{l}-1.548 \\
(-1.95)\end{array}$ & $\begin{array}{c}-.864 \\
(-1.14)\end{array}$ \\
\hline MBEN & $\begin{array}{c}-.001 \\
(-1.75)\end{array}$ & $\begin{array}{l}-.0005 \\
(-1.34)\end{array}$ & $\begin{array}{l}-.0005 \\
(-1.20)\end{array}$ & $\begin{array}{c}-.0003 \\
(-.79)\end{array}$ & $\begin{array}{l}.001 \\
(.45)\end{array}$ & $\begin{array}{l}.001 \\
(.46)\end{array}$ & $\begin{array}{l}.001 \\
(.83)\end{array}$ & $\begin{array}{l}.001 \\
(.82)\end{array}$ \\
\hline CONSTANT & $\begin{array}{l}12.245 \\
(13.00)\end{array}$ & $\begin{array}{l}6.648 \\
(6.20)\end{array}$ & $\begin{array}{l}11.472 \\
(11.94)\end{array}$ & $\begin{array}{l}5.767 \\
(5.32)\end{array}$ & $\begin{array}{r}22.574 \\
(6.00)\end{array}$ & $\begin{array}{r}12.546 \\
(3.19)\end{array}$ & $\begin{array}{r}21.861 \\
(5.73)\end{array}$ & $\begin{array}{r}11.198 \\
(2.82)\end{array}$ \\
\hline $\mathrm{R}^{2}$ & .179 & .274 & .128 & .232 & .161 & .243 & .120 & .215 \\
\hline $\mathrm{F}$ & 9.63 & 15.60 & 7.50 & 14.30 & 4.36 & 6.83 & 3.59 & 6.69 \\
\hline $\mathrm{N}$ & 677 & 677 & 677 & 677 & 357 & 357 & 357 & 357 \\
\hline
\end{tabular}

at-ratios in parentheses. The critical t-ratios at the 5 percent level are 1.64 for a one-tailed test and 1.96 for a two-tailed test. The F-ratio associated with each regression is significant at the 1 percent level. 
TABLE 4

Ordinary Least Squares Regressions of Neonatal Mortality Rates, Model $2^{a}$

\begin{tabular}{|c|c|c|c|c|c|c|c|c|}
\hline \multirow{3}{*}{$\begin{array}{l}\text { Independent } \\
\text { Variable }\end{array}$} & \multicolumn{4}{|c|}{ Panel A: Whites } & \multicolumn{4}{|c|}{ Panel B: Blacks } \\
\hline & \multicolumn{4}{|c|}{ Regression Number } & \multicolumn{4}{|c|}{ Regression Number } \\
\hline & $(4-A 1)$ & $(4-A 2)$ & $(4-A 3)$ & $(4-A 4)$ & $(4-B 1)$ & $(4-B 2)$ & $(4-B 3)$ & $(4-B 4)$ \\
\hline NMR7 0* & -- & .286 & -- & .298 & -- & .264 & -- & .281 \\
\hline & -- & $(9.51)$ & -- & $(9.71)$ & -- & $(6.19)$ & -- & $(6.52)$ \\
\hline $\mathrm{HSP} *$ & $\begin{array}{c}-.046 \\
(-4.46)\end{array}$ & $\begin{array}{l}-.028 \\
(-2.87)\end{array}$ & $\begin{array}{c}-.041 \\
(-3.96)\end{array}$ & $\begin{array}{l}-.022 \\
(-2.18)\end{array}$ & $\begin{array}{l}-.058 \\
(-1.74)\end{array}$ & $\begin{array}{l}-.015 \\
(-.46)\end{array}$ & $\begin{array}{c}-.054 \\
(-1.60)\end{array}$ & $\begin{array}{l}-.010 \\
(-.32)\end{array}$ \\
\hline POV* & $\begin{array}{c}.063 \\
(3.85)\end{array}$ & $\begin{array}{c}.038 \\
(2.41)\end{array}$ & $\begin{array}{c}.060 \\
(3.59)\end{array}$ & $\begin{array}{c}.033 \\
(2.06)\end{array}$ & $\begin{array}{l}.013 \\
(.33)\end{array}$ & $\begin{array}{l}-.013 \\
(-.35)\end{array}$ & $\begin{array}{l}.042 \\
(1.11)\end{array}$ & $\begin{array}{l}.010 \\
(.27)\end{array}$ \\
\hline EMP* & $\begin{array}{l}.002 \\
(.20)\end{array}$ & $\begin{array}{l}.007 \\
(.62)\end{array}$ & $\begin{array}{l}.023 \\
(1.95)\end{array}$ & $\begin{array}{l}.027 \\
(2.38)\end{array}$ & $\begin{array}{l}-.010 \\
(-.32)\end{array}$ & $\begin{array}{l}.005 \\
(.17)\end{array}$ & $\begin{array}{l}.017 \\
(.54)\end{array}$ & $\begin{array}{l}.028 \\
(.93)\end{array}$ \\
\hline OBG & 1.863 & 1.705 & -- & -- & 2.763 & 2.313 & -- & -- \\
\hline & $(6.31)$ & $(6.14)$ & -- & -- & $(4.03)$ & $(3.54)$ & -- & -- \\
\hline POBG & -.004 & -.001 & -- & -- & .006 & .003 & -- & -- \\
\hline & $(-1.40)$ & $(-.44)$ & - & -- & $(.52)$ & $(.22)$ & -- & -- \\
\hline $\mathrm{NEOH}$ & $\begin{array}{r}-28.063 \\
(-1.69)\end{array}$ & $\begin{array}{r}-25.709 \\
(-1.65)\end{array}$ & $\begin{array}{r}-42.645 \\
(-2.52)\end{array}$ & $\begin{array}{r}-39.237 \\
(-2.48)\end{array}$ & $\begin{array}{r}-88.158 \\
(-1.62)\end{array}$ & $\begin{array}{r}-57.643 \\
(-1.11)\end{array}$ & $\begin{array}{r}-87.302 \\
(-1.57)\end{array}$ & $\begin{array}{r}-55.414 \\
(-1.05)\end{array}$ \\
\hline ABPROV & $\begin{array}{l}-5.712 \\
(-3.53)\end{array}$ & $\begin{array}{l}-5.837 \\
(-3.84)\end{array}$ & $\begin{array}{l}-3.688 \\
(-2.27)\end{array}$ & $\begin{array}{l}-3.880 \\
(-2.56)\end{array}$ & $\begin{array}{r}-24.569 \\
(-4.07)\end{array}$ & $\begin{array}{r}-25.080 \\
(-4.38)\end{array}$ & $\begin{array}{r}-17.519 \\
(-2.98)\end{array}$ & $\begin{array}{r}-19.415 \\
(-3.50)\end{array}$ \\
\hline FPCL INPXPOV* & $\begin{array}{l}-2.975 \\
(-2.60)\end{array}$ & $\begin{array}{l}-2.182 \\
(-2.03)\end{array}$ & $\begin{array}{l}-3.442 \\
(-2.93)\end{array}$ & $\begin{array}{l}-2.553 \\
(-2.31)\end{array}$ & $\begin{array}{r}-1.332 \\
(-.91)\end{array}$ & $\begin{array}{l}-.142 \\
(-.10)\end{array}$ & $\begin{array}{l}-1.948 \\
(-1.32)\end{array}$ & $\begin{array}{l}-.582 \\
(-.41)\end{array}$ \\
\hline BCHSPXPOV* & $\begin{array}{r}3.242 \\
(.57)\end{array}$ & $\begin{array}{l}.705 \\
(.13)\end{array}$ & $\begin{array}{r}10.359 \\
(1.80)\end{array}$ & $\begin{array}{l}7.026 \\
(1.30)\end{array}$ & $\begin{array}{r}-28.774 \\
(-2.96)\end{array}$ & $\begin{array}{r}-21.801 \\
(-2.35)\end{array}$ & $\begin{array}{r}-20.723 \\
(-2.15)\end{array}$ & $\begin{array}{r}-14.508 \\
(-1.58)\end{array}$ \\
\hline WICX POV* & $\begin{array}{l}-.078 \\
(-2.63)\end{array}$ & $\begin{array}{c}-.044 \\
(-1.58)\end{array}$ & $\begin{array}{c}-.076 \\
(-2.50)\end{array}$ & $\begin{array}{c}-.041 \\
(-1.42)\end{array}$ & $\begin{array}{l}-.043 \\
(-.93)\end{array}$ & $\begin{array}{l}.015 \\
(.34)\end{array}$ & $\begin{array}{l}-.046 \\
(-.97)\end{array}$ & $\begin{array}{l}.017 \\
(.37)\end{array}$ \\
\hline MPAX POV* & $\begin{array}{c}-.921 \\
(-1.77)\end{array}$ & $\begin{array}{l}-.270 \\
(-.55)\end{array}$ & $\begin{array}{c}-.963 \\
(-1.80)\end{array}$ & $\begin{array}{l}-.306 \\
(-.60)\end{array}$ & $\begin{array}{l}-.272 \\
(-.29)\end{array}$ & $\begin{array}{l}-.274 \\
(-.31)\end{array}$ & $\begin{array}{l}-.080 \\
(-.08)\end{array}$ & $\begin{array}{l}-.092 \\
(-.10)\end{array}$ \\
\hline MPUXPOV* & $\begin{array}{l}.622 \\
(.86)\end{array}$ & $\begin{array}{c}.946 \\
(1.40)\end{array}$ & $\begin{array}{c}.782 \\
(1.06)\end{array}$ & $\begin{array}{l}1.052 \\
(1.52)\end{array}$ & $\begin{array}{l}-.447 \\
(-.39)\end{array}$ & $\begin{array}{l}.115 \\
(.10)\end{array}$ & $\begin{array}{l}.654 \\
(.57)\end{array}$ & $\begin{array}{l}1.089 \\
(1.01)\end{array}$ \\
\hline MPNXPOV* & $\begin{array}{l}1.036 \\
(1.30)\end{array}$ & $\begin{array}{c}.782 \\
(1.04)\end{array}$ & $\begin{array}{l}1.221 \\
(1.49)\end{array}$ & $\begin{array}{c}.896 \\
(1.17)\end{array}$ & $\begin{array}{l}-.320 \\
(-.34)\end{array}$ & $\begin{array}{l}.312 \\
(.35)\end{array}$ & $\begin{array}{l}-.226 \\
(-.24)\end{array}$ & $\begin{array}{l}.427 \\
(.47)\end{array}$ \\
\hline MNEWXPOV* & $\begin{array}{l}-.873 \\
(-.96)\end{array}$ & $\begin{array}{l}-.532 \\
(-.62)\end{array}$ & $\begin{array}{c}-.930 \\
(-1.00)\end{array}$ & $\begin{array}{l}-.547 \\
(-.62)\end{array}$ & $\begin{array}{l}-1.611 \\
(-1.10)\end{array}$ & $\begin{array}{l}-.433 \\
(-.31)\end{array}$ & $\begin{array}{l}-2.964 \\
(-2.04)\end{array}$ & $\begin{array}{l}-1.481 \\
(-1.06)\end{array}$ \\
\hline MBENXPOV* & $\begin{array}{c}-.002 \\
(-1.31)\end{array}$ & $\begin{array}{l}-.001 \\
(-.84)\end{array}$ & $\begin{array}{l}-.001 \\
(-.82)\end{array}$ & $\begin{array}{r}-.0004 \\
(-.32)\end{array}$ & $\begin{array}{l}.002 \\
(.65)\end{array}$ & $\begin{array}{l}.002 \\
(.63)\end{array}$ & $\begin{array}{c}.002 \\
(1.00)\end{array}$ & $\begin{array}{l}.002 \\
(.97)\end{array}$ \\
\hline CONSTANT & $\begin{array}{l}11.209 \\
(13.35)\end{array}$ & $\begin{array}{l}6.111 \\
(6.41)\end{array}$ & $\begin{array}{l}10.606 \\
(12.37)\end{array}$ & $\begin{array}{l}5.410 \\
(5.61)\end{array}$ & $\begin{array}{c}20.811 \\
(6.00)\end{array}$ & $\begin{array}{c}12.018 \\
(3.35)\end{array}$ & $\begin{array}{c}19.688 \\
(5.60)\end{array}$ & $\begin{array}{r}10.457 \\
(2.90)\end{array}$ \\
\hline $\mathrm{R}^{2}$ & .176 & .276 & .125 & .234 & .161 & .246 & .121 & .218 \\
\hline F & 9.42 & 15.68 & 7.28 & 14.45 & 4.37 & 6.94 & 3.63 & 6.82 \\
\hline $\mathrm{N}$ & 677 & 677 & 677 & 677 & 357 & 357 & 357 & 357 \\
\hline
\end{tabular}

asee note to Table 3 . 
with regard to signs and significance levels in the context of Model 2 also are valid in the context of Model 1. In light of the amount of multicollinearity just mentioned, this finding strengthens confidence in the reliability of the estimated effects.

The basic determinants of neonatal mortality in the regressions are female schooling, female poverty levels, the percentage of women employed, and the availability of obstetricians/gynecologists. For whites, the schooling and poverty regression coefficients have the "correct signs" and are statistically significant. For blacks, the poverty effect is practically zero, but the schooling effect is negative and is significant when the lagged neonatal mortality rate is excluded. ${ }^{20}$ For both races, the percentage of women employed is not a statistically significant contributor to birth outcomes. The most anomalous finding in Table 4 or Table 3 is that the coefficient of the obstetrician/gynecologist availability measure (OBG) always is positive, statistically significant, and has a very large tratio. The sensitivity of the other parameter estimates to the omission of $O B G$ and the related variable that gives the percentage of board-certified obstetricians/gynecologists $(P O B G)^{21}$ is considered in regressions (3-A3), $(3-\mathrm{A} 4),(3-\mathrm{B} 3),(3-\mathrm{B} 4),(4-\mathrm{A} 3),(4-\mathrm{A} 4),(4-\mathrm{B} 3)$, and $(4-\mathrm{B} 4)$. On the whole the results are not sensitive to this exclusion. While we have no explanation of the perverse sign of the obstetrician/gynecologist coefficient, ${ }^{22}$ we are convinced that the remaining coefficients are meaningful estimates rather than statistical artifacts.

The six factors or public programs that have been stressed as potential contributors to the acceleration in the downward trend in neonatal mortality since 1964 are neonatal intensive care availability, abortion 
availability, organized family planning availability, BCHS project availability, WIC avallability, and Medicaid. The regressions contain one variable pertaining to each of the five avallability programs and five variables pertaining to the Medicaid financing program. Based on regressions (4-A1) and (4-A2), fourteen of the twenty program coefficients have the anticipated negative signs in the white regressions, including eight of the ten availability coefficients and six of the ten Medicaid coefficients. Based on regressions $(4-B 1)$ and $(4-B 2)$, fifteen of the twenty program coefficients have the anticipated negative signs in the black regressions, including nine of the ten avallability coefficients and six of the ten Medicaid coefficients. BCHS project availability has the "wrong sign" in the two white regressions, and WIC availability has the wrong sign in the black regression that controls for the lagged neonatal mortality rate. Two of the three variables pertaining to Medicaid financing of first-time pregnancies (MPUXPOV* and MPNXPOV*) have positive coefficients for whites and for blacks when the lagged rate is held constant. Moreover, Medicaid payments per adult recipient in AFDC families (MBENXPOV*) are positively related to neonatal mortality rates in the two black equations. Given the high degree of intercorrelation among the variables in the regression and the imprecise measures used, the preponderance of negative effects is an important and impressive finding.

In terms of statistical significance, the hypothesis that no member of the set of program measures has a non-zero effect on neonatal mortality always is rejected at the 1 percent level. With respect to the five specific availability variables, for whites neonatal intensive care, abortion, family planning, and WIC are significant at the 5 percent level in the 
interactive specification that omits the lagged neonatal mortality rate $(4-\mathrm{A} 1) .{ }^{23}$ In the black regression that omits the lagged neonatal mortality rate (4-B1), abortion and BCHS project availability are significant at the 5 percent level, and neonatal intensive care is significant at the 6 percent level. Note that neonatal intensive care is significant at the 5 percent level in the corresponding non-interactive specification (3-B1).

Many fewer of the five Medicaid financing variables are significant than the five availability variables. In particular, for both races there are no significant Medicaid effects either taken together or taken separately at conventional levels when the lagged neonatal mortality rate is a regressor. When the lagged rate is omitted from the white regressions, the set of Medicaid variables is significant at the 5 percent level for whites but not for blacks. These results do not necessarily imply that Medicaid is a less important determinant of birth outcomes than the other programs. Rather, the results simply may reflect the imprecise Medicaid indexes and the relatively large number of correlated regressors that must be used to represent this program.

It is notable that all the program coefficients except for the white and black abortion coefficients fall in absolute value when the lagged neonatal mortality rate is held constant. Since organized family planning clinics and BCHS projects are aimed at the poor counties, presumably with high mortality rates, one can conclude that serial correlation in neonatal mortality and in the program measures dominates reverse causality from low initial health levels to the availability of medical and family planning services for low-income persons in specific areas. Medicaid and WIC also are aimed at the poor, but some caution must be exercised in viewing their 
coefficients in regressions (4-A1) or (4-B1) as unbiased estimates because liberal states with relatively favorable initial health levels may have enacted generous programs. In that case the coefficients from regressions that do not control for the lagged rate are upper bound estimates and those from regressions that do control for the lagged rate are lower bound estimates (because of the serial correlation phenomenon). With respect to neonatal intensive care availability, the coefficients obtained with the lagged rate omitted are upper bound estimates if areas with low initial levels of neonatal mortality encouraged the development of neonatal intensive care units through the political process and lower bound estimates if these units were placed in areas with high initial levels of neonatal mortality. The calculated abortion parameters are insensitive to the treatment of the lagged neonatal mortality rate.

It also is notable that the black abortion and neonatal intensive care effects are two to four times larger than the corresponding white effects depending on specification. These results are important because abortion reform and advances in neonatology -- unlike WIC, Medicaid, BCHS projects and organized family planning clinics -- clearly were not targeted at the poor. Yet the former two developments appear to have had their largest impact on blacks, the group in the population with the lowest income and the largest neonatal mortality rate.

At several points in the discussion of the results, we have referred to problems that arise due to high correlations among regressors. To examine the sensitivity of the findings to multicollinearity, the first two regressions in Panel A and B of Tables 3 and 4 were reestimated after deleting all variables whose coefficients have the "wrong signs" or whose 
coefficients have the "right signs" but t-ratios less than one in absolute value. $^{24}$ The resulting Mode1 1 (non-interactive) regressions are presented in Table 5, and the Model 2 (interactive) regressions are presented in Table 6. Since regressors were deleted on a race-specific basis, the independent variables in the black equations are not the same as in the white equations.

In many instances the magnitudes of the coefficients in Tables 5 and 6 differ from the magnitudes of the corresponding coefficients in Tables 3 and 4. This result is not surprising. What is somewhat surprising is that the signs and statistical significance of the various variables are very similar in the limited and full models. This finding strengthens the confidence in the conclusions reached earlier while underscoring that point estimates must be regarded with some caution. Note, however, that the black abortion effect still exceeds the white effect by a factor in excess of 4. Moreover, the black neonatal care effect exceeds the white effect by a factor that ranges between 1.4 and 2. Note also that Tables 5 and 6 suggest that Medicaid financing of newborn care is important in black birth outcomes, while Medicaid financing of prenatal care for first-time pregnancies is important in white birth outcomes. This is a tentative finding because it emerges only when the set of Medicaid regressors is truncated. But it is consistent with results that indicate that white neonatal mortality rates are more sensitive to the receipt of early prenatal care than black rates (Corman and Grossman in progress).

To examine the relative contributions of schooling, poverty, female employment, the avallability of obstetricians/gynecologists, and the program measures to the recent U.S. neonatal mortality experience, we apply 
TABLE 5

Ordinary Least Squares Regressions of Neonatal Mortality Rates, Mode1 1, Limited Set of Regressors

\begin{tabular}{|c|c|c|c|c|}
\hline \multirow[b]{2}{*}{$\begin{array}{l}\text { Independent } \\
\text { Variable }\end{array}$} & \multicolumn{2}{|c|}{ Panel A: Whites } & \multicolumn{2}{|c|}{ Panel B: Blacks } \\
\hline & $\frac{\text { Regression }}{(5-\mathrm{A} 1)}$ & $\frac{\text { Number }}{(5-A 2)}$ & $\frac{\text { Regression }}{(5-\mathrm{B} 1)}$ & $\frac{\text { Number }}{(5-\mathrm{B} 2)}$ \\
\hline NMR70* & -- & $\begin{array}{c}.293 \\
(9.46)\end{array}$ & -- & $\begin{array}{c}.276 \\
(6.62)\end{array}$ \\
\hline $\mathrm{HSP} *$ & $\begin{array}{l}-.030 \\
(-3.02)\end{array}$ & $\begin{array}{l}-.012 \\
(-1.25)\end{array}$ & $\begin{array}{l}-.038 \\
(-1.87)\end{array}$ & $\begin{array}{l}-.007 \\
(-.34)\end{array}$ \\
\hline $\mathrm{POV} *$ & $\begin{array}{l}.020 \\
(2.48)\end{array}$ & $\begin{array}{c}.012 \\
(1.50)\end{array}$ & $\begin{array}{l}-- \\
--\end{array}$ & -- \\
\hline $\mathrm{NEOH}$ & $\begin{array}{r}-49.701 \\
(-3.00)\end{array}$ & $\begin{array}{r}-43.285 \\
(-2.78)\end{array}$ & $\begin{array}{r}-95.790 \\
(-1.82)\end{array}$ & $\begin{array}{r}-61.404 \\
(-1.23)\end{array}$ \\
\hline ABPROV & $\begin{array}{l}-2.876 \\
(-1.82)\end{array}$ & $\begin{array}{l}-3.280 \\
(-2.22)\end{array}$ & $\begin{array}{r}-17.865 \\
(-3.38)\end{array}$ & $\begin{array}{r}-20.077 \\
(-4.02)\end{array}$ \\
\hline FPCLINP & $\begin{array}{l}-.521 \\
(-1.64)\end{array}$ & $\begin{array}{l}-.359 \\
(-1.20)\end{array}$ & -- & $\begin{array}{l}-- \\
--\end{array}$ \\
\hline BCHSP & - & $\begin{array}{l}-- \\
--\end{array}$ & $\begin{array}{r}-11.273 \\
(-2.05)\end{array}$ & $\begin{array}{l}-7.193 \\
(-1.38)\end{array}$ \\
\hline WIC & $\begin{array}{l}-.024 \\
(-2.95)\end{array}$ & $\begin{array}{l}-.011 \\
(-1.39)\end{array}$ & $\begin{array}{c}-.037 \\
(-1.52)\end{array}$ & $\begin{array}{l}.004 \\
(.18)\end{array}$ \\
\hline MPA & $\begin{array}{l}-.506 \\
(-3.67)\end{array}$ & $\begin{array}{l}-.280 \\
(-2.12)\end{array}$ & -- & $\begin{array}{l}-- \\
--\end{array}$ \\
\hline MNEW & $\begin{array}{l}-- \\
--\end{array}$ & $\begin{array}{l}-- \\
--\end{array}$ & $\begin{array}{l}-1.375 \\
(-1.83)\end{array}$ & $\begin{array}{c}-.759 \\
(-1.06)\end{array}$ \\
\hline MBEN & $\begin{array}{l}-.001 \\
(-1.56)\end{array}$ & $\begin{array}{l}-.0004 \\
(-1.11)\end{array}$ & -- & $\begin{array}{l}-- \\
-\end{array}$ \\
\hline CONSTANT & $\begin{array}{l}12.131 \\
(15.59)\end{array}$ & $\begin{array}{l}6.697 \\
(7.20)\end{array}$ & $\begin{array}{l}22.624 \\
(13.98)\end{array}$ & $\begin{array}{r}13.018 \\
(6.18)\end{array}$ \\
\hline $\mathrm{R}^{2}$ & .117 & .222 & .110 & .209 \\
\hline $\mathbf{F}$ & 11.11 & 21.11 & 7.20 & 13.19 \\
\hline $\mathrm{N}$ & 677 & 677 & 357 & 357 \\
\hline
\end{tabular}

asee note to Table 3 . 
TABLE 6

Ordinary Least Squares Regressions of Neonatal Mortality Rates, Model 2, Limited Set of Regressors

\begin{tabular}{|c|c|c|c|c|}
\hline $\begin{array}{l}\text { Independent } \\
\text { Variable }\end{array}$ & $\frac{\text { Panel A: }}{\frac{\text { Regression }}{(6-\mathrm{Al})}}$ & $\frac{\text { Whites }}{\frac{\text { Number }}{(6-A 2)}}$ & $\frac{\text { Panel B: }}{\text { Regression }}$ & $\frac{\frac{\text { B1acks }}{(6-B 2)}}{(6-B m b e r}$ \\
\hline NMR70* & $\begin{array}{l}-- \\
--\end{array}$ & $\begin{array}{c}.299 \\
(9.77)\end{array}$ & $\begin{array}{l}-- \\
--\end{array}$ & $\begin{array}{l}.279 \\
(6.79)\end{array}$ \\
\hline $\mathrm{HSP} *$ & $\begin{array}{l}-.035 \\
(-3.50)\end{array}$ & $\begin{array}{l}-.015 \\
(-1.56)\end{array}$ & $\begin{array}{l}-.059 \\
(-2.24)\end{array}$ & $\begin{array}{l}-.010 \\
(-.41)\end{array}$ \\
\hline POV* & $\begin{array}{l}.055 \\
(3.77)\end{array}$ & $\begin{array}{l}.030 \\
(2.18)\end{array}$ & $\begin{array}{l}-- \\
--\end{array}$ & $\begin{array}{l}-- \\
--\end{array}$ \\
\hline $\mathrm{NEOH}$ & $\begin{array}{r}-47.110 \\
(-2.81)\end{array}$ & $\begin{array}{r}-42.168 \\
(-2.69)\end{array}$ & $\begin{array}{c}-90.103 \\
(-1.71)\end{array}$ & $\begin{array}{c}-59.190 \\
(-1.19)\end{array}$ \\
\hline ABPROV & $\begin{array}{l}-3.281 \\
(-2.08)\end{array}$ & $\begin{array}{l}-3.390 \\
(-2.29)\end{array}$ & $\begin{array}{r}-17.508 \\
(-3.23)\end{array}$ & $\begin{array}{r}-20.047 \\
(-3.92)\end{array}$ \\
\hline FPCLINPXPOV* & $\begin{array}{l}-2.929 \\
(-2.56)\end{array}$ & $\begin{array}{l}-2.273 \\
(-2.12)\end{array}$ & -- & $\begin{array}{l}-- \\
--\end{array}$ \\
\hline BCHSPXPOV * & -- & $\begin{array}{l}-- \\
--\end{array}$ & $\begin{array}{r}-19.216 \\
(-2.07)\end{array}$ & $\begin{array}{l}-13.823 \\
(-1.58)\end{array}$ \\
\hline WICXPOV* & $\begin{array}{l}-.060 \\
(-2.08)\end{array}$ & $\begin{array}{l}-.028 \\
(-1.04)\end{array}$ & $\begin{array}{l}-.030 \\
(-.75)\end{array}$ & $\begin{array}{r}.027 \\
(.69)\end{array}$ \\
\hline MPAXPOV* & $\begin{array}{l}-1.454 \\
(-3.00)\end{array}$ & $\begin{array}{l}-.794 \\
(-1.73)\end{array}$ & -- & -- \\
\hline MNEWXPOV* & -- & $\begin{array}{l}-- \\
--\end{array}$ & $\begin{array}{l}-1.780 \\
(-1.53)\end{array}$ & $\begin{array}{l}-1.291 \\
(-1.17)\end{array}$ \\
\hline MBENXPOV* & $\begin{array}{l}-.002 \\
(-1.27)\end{array}$ & $\begin{array}{l}-.001 \\
(-.68)\end{array}$ & $\begin{array}{l}-- \\
--\end{array}$ & $\begin{array}{l}-- \\
--\end{array}$ \\
\hline CONSTANT & $\begin{array}{l}11.281 \\
(15.24)\end{array}$ & $\begin{array}{l}6.186 \\
(7.13)\end{array}$ & $\begin{array}{c}22.512 \\
(12.302)\end{array}$ & $\begin{array}{r}12.777 \\
(5.70)\end{array}$ \\
\hline $\mathrm{R}^{2}$ & .110 & .222 & .108 & .212 \\
\hline F & 10.35 & 21.10 & 7.04 & 13.40 \\
\hline $\mathrm{N}$ & 677 & 677 & 357 & 357 \\
\hline
\end{tabular}

asee note to Table 3 . 
the coefficients of regressions (3-A1), (3-A2), (4-Al), (4-A2), (5-Al), $(5-A 2),(6-A 1),(6-A 2),(3-B 1),(3-B 2),(4-B 1),(4-B 2),(5-B 1),(5-B 2)$, (6-B1), and (6-B2) to trends in the exogenous variables between 1964 and 1977.25 The extrapolations start in 1964 because that year marked the beginning of the acceleration in the downward trend in neonatal mortality. Extrapolations end in 1977 because the regressions pertain to that year. The results of estimating the implied changes in white and black neonatal mortality rates due to selected factors are shown in Tables 7 and 8 , respectively.

In the period at issue the white neonatal mortality rate declined by 7.5 deaths per thousand 1ive births, from 16.2 to 8.7 . The black neonatal mortality rate declined by 11.5 deaths per thousand live births, from 27.6 to 16.1. The statistical analysis "explains" approximately 29 percent of the white decline on average, with a range between 21 percent and 40 percent (see the last row of Table 7). The statistical analysis explains 32 percent of the black decline on average, with a range between 16 percent and 45 percent (see the last row in Table 8 ).

For blacks, the increase in abortion availability is the single most important factor in the reduction in the neonatal mortality rate. Not only does the growth in abortion dominate the other program measures, but it also dominates trends in schooling, poverty, female employment, and physician availability. The actual reduction due to abortion amounts to 1.2 deaths per thousand live births on average (see the next to the last column in Table 8 ) or 10 percent of the observed decline. Moreover, the estimated 


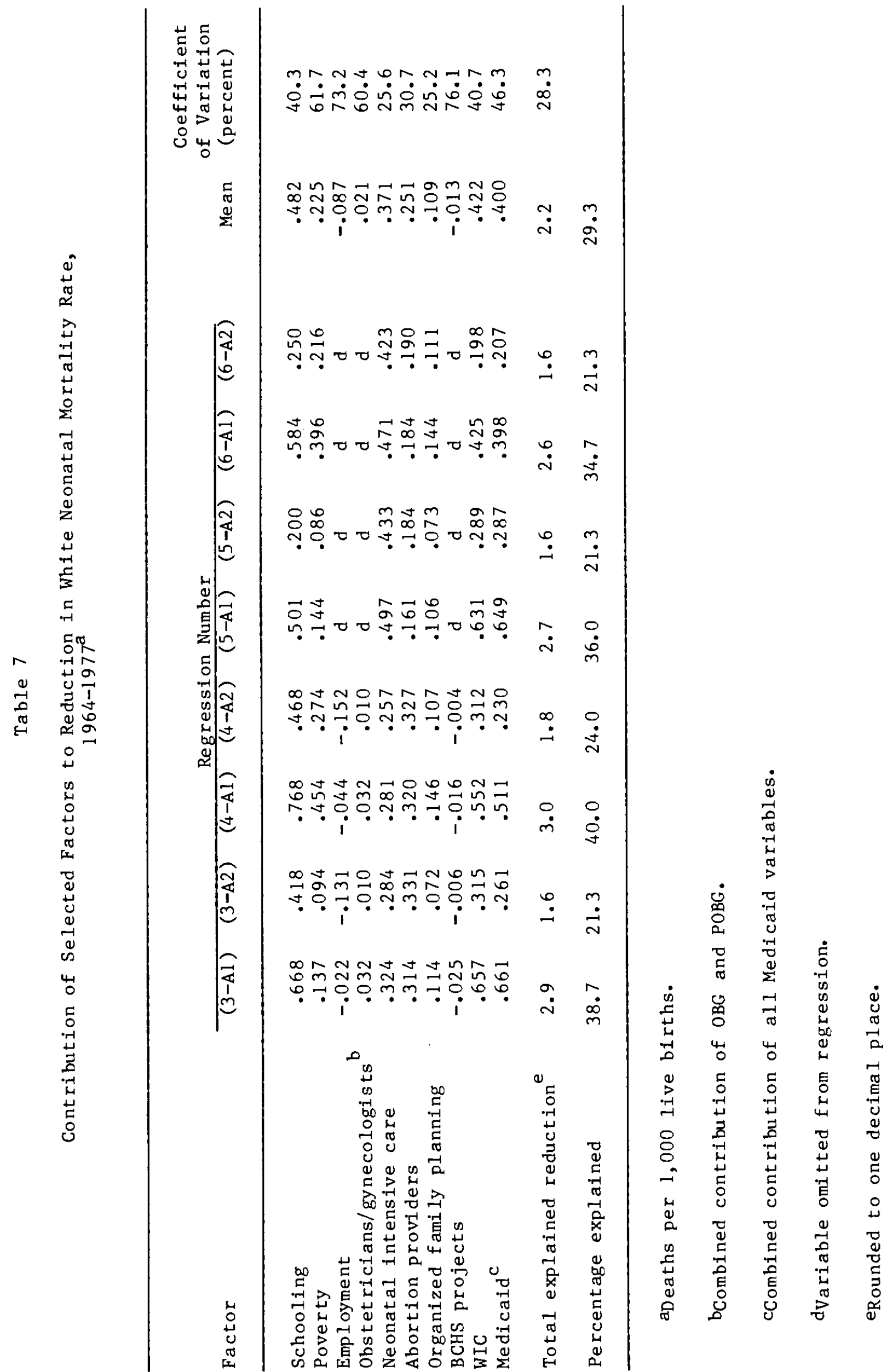




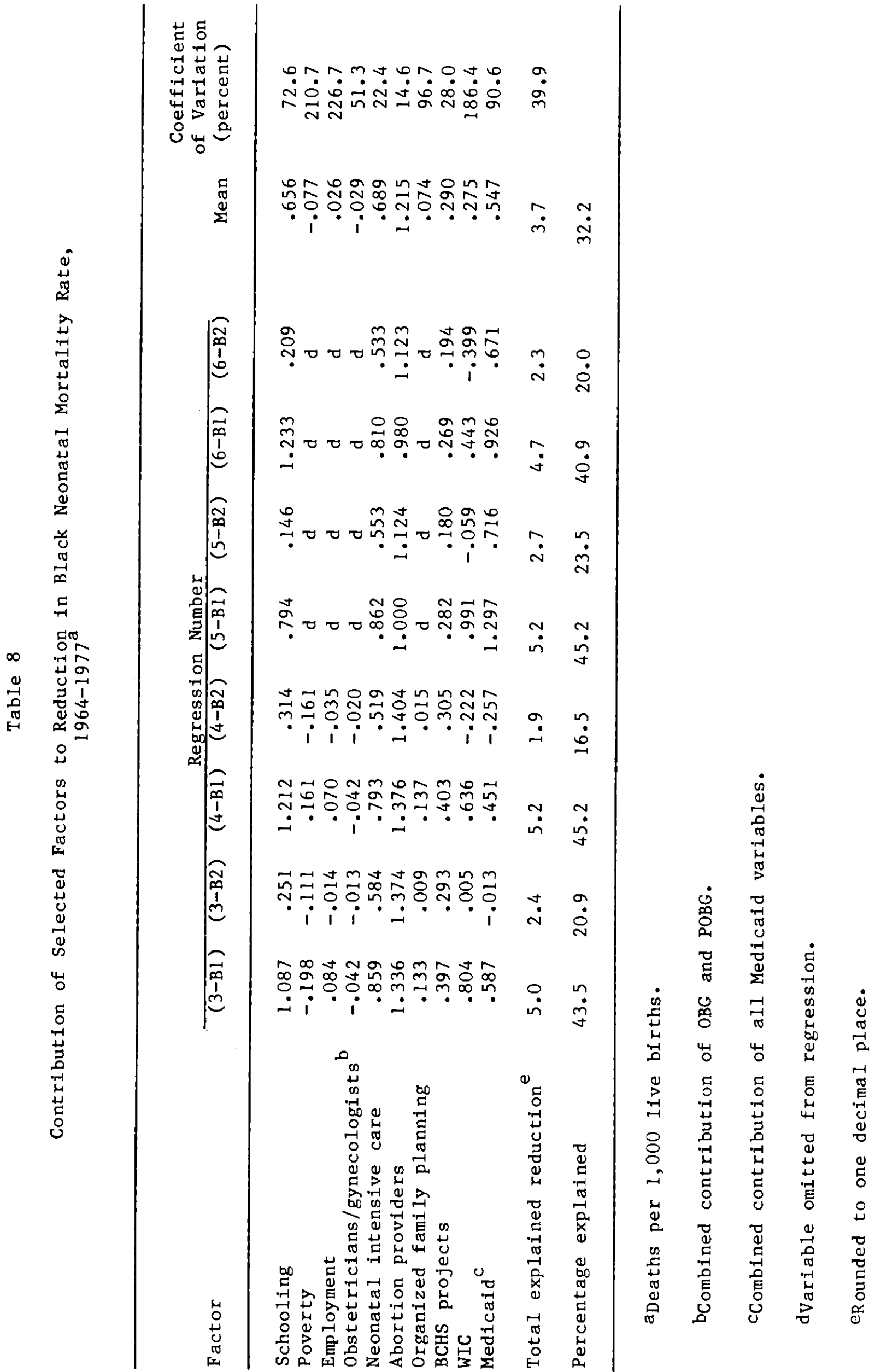


contribution of abortion is almost twice as great as the next largest factor and is very stable across the eight alternative regression specifications. Its coefficient of variation of roughly 15 percent is smaller than those of the other nine factors (see the last column of Table 8).

The rise in neonatal intensive care availability is the second-most important factor in the decrease in black neonatal mortality, and the rise in female schooling is the third-most important factor. Both effects amount to declines of .7 deaths per thousand live births, but the coefficient of variation of the neonatal intensive care contribution ( 22 percent) is much smaller than that of schooling (73 percent). The Medicaid contribution ( .5 deaths per thousand live births) ranks fourth on average but has a very large coefficient of variation ( 91 percent). The BCHS project effect, which equals a decline of .3 deaths per thousand live births, is smaller than the Medicaid effect but much more stable across alternative specifications (coefficient of variation $=28$ percent). The reduction in black neonatal mortality due to WIC also equals . 3 deaths per thousand live births, but the coefficient of variation is nearly 200 percent. The contributions of the remaining four factors are all less than .1 deaths per thousand live births in absolute value. 26

The results of the white extrapolations are less dramatic than those of the blacks and less clearcut. The increase in white female schooling makes the largest contribution to the decline in white neonatal mortality (.5 deaths per thousand live births). The schooling factor is followed in importance by WIC, Medicaid, and neonatal intensive care availability (.4 deaths per thousand live births each). The rise in abortion availability ranks as the fifth-leading contributor ( .3 deaths per thousand live 
births); the reduction in poverty ranks sixth (.2 deaths per thousand live births); and the expansion in organized family planning availability ranks seventh (.l deaths per thousand live births). Note that the range of black effects is much larger than the range of white effects both in absolute and in relative terms. For blacks, the ratio of the largest effect to the sixth largest effect equals 4, while for whites it equals 2.5 . Note also that the correlation between the black and white contributions is positive but not substantial. The Spearman rank correlation coefficient is .53 , and the product-moment correlation coefficient also is .53 . Note finally that the abortion and neonatal intensive care contributions may loom larger in white birth outcomes than the rankings suggest. This is because the estimated effects of these two factors are very stable across alternative specifications. Their coefficients of variation (26 percent for neonatal intensive care and 31 percent for abortion) are smaller than those pertaining to schooling, WIC, and Medicaid.

To summarize, the extrapolations point to the importance of abortion availability, neonatal intensive care availability, females schooling levels, and to a lesser extent Medicaid, BCHS projects, and WIC in trends in black neonatal mortality between 1964 and 1977 . They also underscore the importance of schooling, neonatal intensive care, abortion, Medicaid, WIC, and to a lesser extent poverty and organized family planning clinics in trends in white neonatal mortality in those years.

To the extent that very 111 neonates die in the postneonatal period, one can argue that the above findings overstate the importance of neonatal intensive care availability in race-specific birth outcomes. Yet the postneonatal mortality rate has fallen every year since 1964 for both races, 
suggesting that this argument is not relevant. At the same time, the results do not imply that the construction and subsidization of additional neonatal intensive care units has a more favorable benefit-cost ratio than an expansion in BCHS projects for blacks if, for example, these were competing programs. Although the neonatal intensive care effect exceeds the BCHS project effect by .4 deaths per thousand live births, the costs of $M$ and I projects and CHCs probably are smaller than the costs of constructing and maintaining sophisticated neonatal intensive care units. A similar comment applies to the .3 deaths per thousand live births differential between the white neonatal intensive care and organized family planning effects. Indeed, the cost of providing appropriate birth control information to poor women undoubtedly is less than the cost of providing them with prenatal and neonatal care services.

Our results can be compared to those contained in the study by Grossman and Jacobowitz (1981). Our estimates confirm Grossman and Jacobowitz's conclusion with respect to the key role of abortion in black birth outcomes. Our schooling effects are somewhat larger than theirs, which implies that this variable may operate by influencing the mix of inputs selected by families to produce healthy infants. Finally, we provide evidence of the roles of neonatal intensive care units, WIC, and CHCs in birth outcomes, which is not contained in their study.

Our results are relevant to the actual and potential impacts on neonatal mortality of a number of dramatic policy reversals by the Reagan Administration since the beginning of 1981 . We refer to budget cutbacks which curtailed the rates of growth in such programs as WIC, Medicaid, M and I projects, CHCs, and subsidized family planning services. When infla- 
tion is taken into account, the absolute size of some of these programs declined in real terms. In spite of these cutbacks, the infant mortality rate declined from 12.6 deaths per thousand live births in 1980 to 11.2 deaths per thousand live births in 1982, and the neonatal mortality rate fell from 8.5 deaths per thousand live births in 1980 to 7.6 deaths per thousand live births in $1982 .^{27}$

Why did the infant mortality rate continue to fall after 1980 ? Our results suggest that the detrimental effects of reduced spending levels for social programs may have been more than offset by the continued growth in abortion availability, ${ }^{28}$ neonatal intensive care availability, and female schooling levels. Of course, the cutbacks may have lagged impacts on neonatal mortality. In any event our findings imply that the program reductions may have retarded the rate of decline in the neonatal mortality rate of the poor since 1980 .

Our results also are relevant to the current U.S. policy debate with respect to attempts by the Right to Life movement and its supporters in Congress to outlaw abortion except when it is necessary to preserve a pregnant woman's life. During the past few years, the anti-abortion movement has tried to achieve this goal either by means of a constitutional amendment or an act of Congress. Our estimates indicate that, if these efforts are successful, neonatal mortality, especially among blacks, may fall slower than otherwise and may even rise. 


\section{FOOTNOTES}

* Research for this paper except for Hope Corman's time was supported by Grant Number 5 R01 HD16316 from the National Institute of Child Health and Human Development to the National Bureau of Economic Research. Hope Corman's time was supported directly by the National Bureau of Economic Research. We are indebted to the following people for providing us with data: Kathleen Bajo of Ross Laboratories; Richard Bohrer, Edward Duffy, Joann Gephart, and Robert Nelson of the Bureau of Health Care Delivery and Assistance, DHHS; Stephen M. Davidson of the Northwestern University Program in Hospital and Health Services Administration; Gary Davis of the American Hospital Association; Jaqueline D. Forrest and Stanley K. Henshaw of the Alan Guttmacher Institute; and Letty Wunglueck of the Health Care Financing Administration. We are also indebted to Peter Budetti of the University of California at San Francisco Health Policy Program and to Jacqueline D. Forrest and Stanley K. Henshaw for helpful comments and suggestions. Finally, we wish to thank Emil Berendt and Theodore J. Joyce for research assistance. This paper has not undergone the review accorded official NBER publications; in particular, it has not been submitted for approval by the Board of Directors.

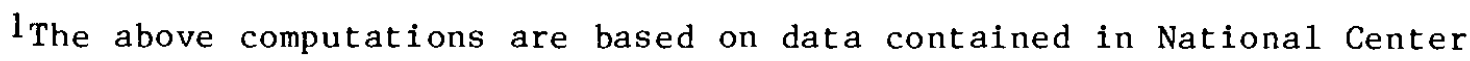
for Health Statistics (1983).

${ }^{2}$ The perinatal period is the period around the time of birth, generally defined as from 20 weeks of gestation up to 7 days of 1 ife.

3 Brief descriptive and historical information concerning these factors is as follows. Medicaid, enacted in 1965 as Title XIX of the Social Security Act of 1935, is the joint Federal-state program to finance the 
medical care services of low-income families who are covered by the ald to families with dependent children (AFDC) program. Maternal and infant care projects originated in the 1963 amendment to Title V of the Social Security Act. The amendment provides special Federal grants for projects designed to provide adequate prenatal and obstetrical care to reduce the incidence of mental retardation and other conditions caused by childbearing complications as well as to lower infant and maternal mortality. The program to create and fund community health centers was started by the office of Economic Opportunity as part of the War on Poverty in 1965. By 1973 overall control of the centers had been shifted to the Bureau of Health Care Delivery and Assistance (formerly called the Bureau of Community Health Services), DHHS. CHCs deliver comprehensive ambulatory care, both primary and preventive, to poverty populations in medically underserved areas. The Special Supplemental Food Program for Women, Infants, and Children (WIC program) was authorized by a 1972 amendment to the Child Nutrition Act of 1966. Under the program the Federal government gives cash grants to state health departments and local health clinics to provide special nutritious food supplements to low-income pregnant and lactating women, infants, and children up to four years of age who are nutritional risks. Federal subsidization of family planning services for low-income women originated in the 1967 amendments to the Social Security Act. Federal efforts in this area were expanded by the Family Planning Services and Population Research Act of 1970 and by the 1972 amendments to the Social Security Act. These subsidies go to family planning clinics organized by hospitals, state and local health departments, Planned Parenthood, and other agencies. Prior to 1967 all states of the United States had laws which permitted abortion only 
when it was necessary to preserve a pregnant woman's life. By the middle of 1970, sixteen states had reformed their laws to increase the number of circumstances under which abortions could be performed. In 1973 the Supreme Court ruled most restrictive state laws unconstitutional. Information on neonatal intensive care unt ts is provided below.

${ }^{4}$ The indirect costs of obtaining a good are generated by the time spent traveling, waiting, and obtaining information about the good. We use the terms cost and availability as synonyms. In particular, with other factors held constant, an increase in availability is associated with reductions in direct and indirect costs.

${ }^{5}$ The variable b can be interpreted as the probability of a low-birth weight birth.

${ }^{6}$ Some of the nonmedical inputs, such as maternal cigarette smoking and alcohol use, have negative marginal products in the birth weight production function.

7The input demand functions are reduced form equations because they are obtained by maximizing a utility function subject to production and resource constraints. Note that the above specification contains the restriction that prenatal care and the exogenous risk factors affect survival only through their impacts on birth weight, but this restriction does not affect the nature of the reduced form. Note also that such endogenous risk factors as mother's age at birth, parity, gestational age, and legitimacy status of the birth can be incorporated into the birth weight production function. This would add equations for each of these factors to the reduced form but would not alter the reduced form survival equation (7). As explained below, we focus on 


$$
\text { F }-4
$$

the estimation of equation (7) in this paper.

${ }^{8}$ For an attempt to estimate structural neonatal mortality rate production functions, see Corman and Grossman (in progress).

${ }^{9}$ Potential endogeneity problems are explored in more detail in Section II.

10 One county with a population of at least 50,000 persons in 1970 was eliminated from the sample because it was the only such county characterized as an isolated rural county with no incorporated place with a population of at least 2,500 persons in 1970. In addition, Washington, D.C. was excluded because of difficulty of defining its relevant market area. In particular, many nonresidents use its sophisticated neonatal intensive care hospitals, and these facilities are not likely to be widely available to its relatively large black population.

${ }^{1}$ These advances are described by the American Academy of Pediatrics (1977), the Commlttee on Perinatal Health (1977), and Budetti et al. (1981).

${ }^{12}$ In the context of the household production function model of consumer behavior, the sign of the efficiency effect in a particular output demand function is ambiguous if, for example, an increase in the mother's schooling raises her productivity in the production of healthy infants by a smaller percentage than her productivity in other household activities (Grossman 1972; Michael 1972). Nevertheless, we think that it is reasonable to expect a negative schooling coefficient in the neonatal mortality rate regression.

${ }^{13}$ This assumes that the production of healthy infants is more timeintensive than the production of other commodities. Note that the 
employment variable is a positive correlate of the opportunity cost of a potential mother's time, but it is also a negative correlate of the amount of time that she allocates to the production of healthy fetuses. That is, women in families with strong preferences for healthy offspring are less likely to work when they are pregnant, no matter what their opportunity cost is. Put differently, the employment variable is endogenous and may be correlated with the disturbance term in the infant survival demand function. We use this variable in the regressions because it is the only available measure of the opportunity cost of time and because the regression coefficients of the other variables are only slightly altered by its exclusion.

${ }^{14} \mathrm{~A}$ more detailed justification for the aggregation of $\mathrm{M}$ and $\mathrm{I}$ projects and CHCs is contained in the Appendix.

15 Federal funding of abortions resumed temporarily in February 1980, pending a review by the U.S. Supreme Court of a ruling by Federal District Judge John F. Dooling Jr. that declared the Hyde Amendment unconstitutional. In June 1980 the Supreme Court reversed Judge Dooling's decision and upheld the constitutionality of the Hyde Amendment.

16 The above point is best illustrated in the context of the following pooled cross-sectional time-series regression model:

$$
d_{j t}=\alpha_{0}+\alpha_{1} x_{j t}+\alpha_{2} d_{j t-1} \text {. }
$$

Here $d_{j t}$ is the neonatal mortality rate in the $j t h$ county in year $t$ and $x_{j t}$ is an availability measure. Assume that initially, the correlation between $x_{j t}$ and $d_{j t-1}$ is positive, reflecting the placement of the public program in counties with above average infant mortality rates. Ultimately, however, the correlation between the current program level and lagged mor- 


$$
F-6
$$

tality will become negative if $x_{j t}$ has a substantial impact on $d_{j t}$ each year and if the correlation between $x_{j t}$ and $x_{j t+l}$ is positive and fairly large. If the initial correlation between $x_{t}$ and $d_{t-1}$ is negative, reflecting placement of programs in low mortality areas then the correlation between these two variables will become more negative the longer the program is in effect. Either way, inclusion of the lagged mortality rate results in coefficients being biased toward zero. Clearly this model could be modified to allow the availability measure to affect neonatal mortality with a lag. Note that, although the lagged neonatal mortality rate used empirically pertains to 1970 , the point just made is relevant to programs such as WIC that began after 1970 if the level of WIC is serially correlated with programs that began before 1970. Note also that estimation of the preceding model or one that relates the change in neonatal mortality to changes in exogenous variables is beyond the scope of this paper because county- or area-specific time series for a number of key independent variables are not available. As it stands, the creation of our data base required a considerable amount of time and effort.

${ }^{17}$ If serial correlation bias exists and the sign of reverse causality bias is zero or negative, then inclusion of the lagged neonatal mortality rate will provide lower bound estimates of the absolute values of program effects, and exclusion of this variable will provide upper bound estimates of program effects. On the other hand, if serial correlation bias exists and the sign of reverse causality bias is positive, then inclusion or exclusion of the lagged mortality results in program coefficients being biased toward zero. In this case, the specification with the lower program coefficients will indicate which bias is stronger. That is, if inclusion 
(exclusion) of the lagged rate results in lower coefficients, this implies that the serial correlation bias (reverse causality bias) dominates.

$18_{\text {As }}$ indicated in Section $I$, the coefficient on $x_{p j}$ in equation (12) could be positive if the program at issue lowers the price of medical care paid by the poor and therefore lowers the cost of a birth.

${ }^{19}$ The above approach differs from that of Grossman and Jacobowitz (1981). They estimate the fraction of births to low-income women and then fit an equation of the form

$$
\mathrm{d}_{j}=\beta_{0}+\left(\alpha_{0}-\beta_{0}\right) \mathrm{k}_{j}+\alpha_{1} \mathrm{k}_{\mathrm{j}} \mathrm{x}_{\mathrm{pj}} \text {. }
$$

We do not adopt this procedure because we focus on the reduced form, and $k_{j}$ is an endogenous variable.

${ }^{20}$ The numerically small and statistically insignificant black schooling effect in regression (4-B2) reflects at least in part the serial correlation bias discussed in Section II. In particular, the black schooling variable rose more rapidly both in absolute and in percentage terms than the white schooling variable between 1964 and 1977.

$21_{\mathrm{OBG}}$ and $\mathrm{POBG}$ are positively correlated in the white sample $(\mathrm{r}=.13)$ and negatively correlated in the black sample $(r=-.07)$. When OBG alone is deleted from the regressions, the coefficient of POBG is positive and insignificant in each sample. The coefficients of the other variables are very similar to those obtained when both $O B G$ and POBG are deleted.

${ }^{22}$ The positive relationship between the physician variable and the neonatal mortality rate may reflect causality from the latter to the former. In particular, physicians may be attracted to areas where neonatal mortality rates are high and the demand for their services is relatively 
large. In principle, the use of the lagged neonatal mortality rate controls for this potential reverse causality relationship, but apparently it is not successful in this case. At tempts to fit the neonatal mortality equation by two-stage least squares with the physician variable treated as endogenous also were not successful.

${ }^{23} \mathrm{~A}$ one-tailed test is employed because the alternative hypothesis is that each coefficient is negative.

240 a race-specific basis, a variable was retained if it had the correct sign and a t-ratio greater than one in at least one of the four relevant regressions. There was one exception to this algorithm. For whites, the percentage of board-certified obstetricians/gynecologists was deleted because it had a positive and significant effect when the physician availability measure was deleted.

25 The sources for the values of the independent variables in the extrapolations, and the assumptions that underlie these values are avaflable in the Appendix to this paper, which is available on request.

${ }^{26}$ The obstetrician/gynecologist component is very smal1 in absolute value for blacks and positive for whites because the number of obstetricians/ gynecologists per thousand women aged 15 to 44 fell slightly between 1964 and 1977.

27 Race-specific data are not yet available for years after 1980 . 28 Recal1 that Cates (1981) reports that the ban on Federal funding of abortions under Medicaid has had little impact on the number of abortions obtained by low-income pregnant women. 
REFERENCES

American Academy of Pediatrics, Committee on Fetus and Newborn. Standards and Recommendations for Hospital Care of Newborn Infants, 1974-1977. Sixth Edition. Evanston, Illinois: American Academy of Pediatrics, 1977.

Becker, Gary S., and Lewis, H. Gregg. "On the Interaction between the Quantity and Quality of Children." In New Economic Approaches to Fertility, edited by T.W. Schultz. Proceedings of a conference sponsored by the National Bureau of Economic Research and the Population Council. Journal of Political Economy, 81 , No. 2, Part II (March/April 1973).

Ben-Porath, Yoram, and Welch, Finis. "Do Sex Preferences Really Matter?" The Quarterly Journal of Economics, 90, No. 2 (May 1976). Brooks, Charles H. "Infant Mortality in SMSAs Before Medicaid: Test of a Causa1 Mode1." Health Services Research 13, No. 1 (Spring 1978). Budetti, Peter et al. "Costs and Effectiveness of Neonatal Intensive Care." In The Implications of Cost-Effectiveness Analysis of Medical Technology. Office of Technology Assessment, U.S. Congress. Washington, D.C.: U.S. Government Printing Office, 1981. Cates, Willard Jr. "The Hyde Amendment in Action: How Did the Restriction of Federal Funds for Abortion Affect Low-Income Women." Journal of the American Medical Association, 246, No. 1. (September 1981).

Committee on Perinatal Health. Toward Improving the Outcome of Pregnancy: Recommendations for the Regional Development of Maternal and Perinatal Health Services. White Plains, New York: National Foundation of the 


$$
\mathrm{R}-2
$$

March of Dimes, 1977.

Corman, Hope, and Grossman, Michael. "Birth Outcome Production Functions

in the U.S." In progress.

David, Richard J., and Siegel, Earl. "Decline in Neonatal Mortality, 1968 to 1977: Better Babies or Better Care." Pediatrics, 71, No. 4 (Apri1 1983).

Dryfoos, Joy G. "The United States National Family Planning Program, 1968-74." Studies in Family Planning, 7, No. 3 (March 1976). Eisner, Victor et al. "Improvement in Infant and Perinatal Mortality in the United States, 1965-1973." American Journal of Public Health, 68, No. 4 (Apri1 1978).

Fuchs, Victor R. "Some Economic Aspects of Mortality in Developed Countries." In The Economics of Health and Medical Care, edited by Mark Perlman. London: MacMillan, 1974.

Goldman, Fred, and Grossman, Michael. "The Impact of Public Health Policy: The Case of Community Health Centers." National Bureau of Economic Research Working Paper No. 1020, November 1982.

Gortmaker, Steven L. "Poverty and Infant Mortality in the United States." American Sociological Review, 44, No. 2 (Apri1 1979).

Grossman, Michae1. The Demand for Health: A Theoretical and Empirical

Investigation. New York: Columbia University Press for the National Bureau of Economic Research, 1972.

Grossman, Michael, and Jacobowitz, Steven. "Variations in Infant Mortality Rates Among Counties of the United States: The Roles of Public Policies and Programs." Demography, 18, No. 4 (November 1981). Hadley, Jack. More Medical Care, Better Health? Washington, D.C. 
The Urban Institute, 1982.

Harris, Jeffrey E. "Prenatal Medical Care and Infant Mortality." In

Economic Aspects of Health, edited by Victor R. Fuchs. Chicago:

University of Chicago Press for the National Bureau of Economic Research, 1982.

Kleinman, Joel C., et al. "A Comparison of 1960 and 1973-1974 Early

Neonatal Mortality in Selected States." American Journal of

Epidemi ology, 108 (1978).

Lee, Kwang-Sun, et al. "Neonatal Mortality: An Analysis of the Recent

Improvement in the United States." American Journal of Public Health,

70, No. 1 (January 1980).

Lewit, Eugene M. "The Demand for Prenatal Care and the Production of Healthy Infants." In Volume III of the Annual Series of Research in

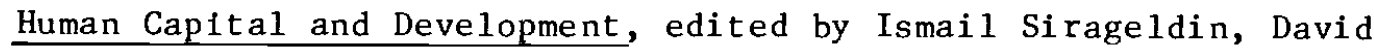
Salkever, and Alan Sorkin. Greenwich Connecticut: JAI Press, Inc., 1983. Michae1, Robert T. The Effects of Education on Efficiency in Consumption.

New York: Columbia University Press for the National Bureau of Economic Research, 1972.

Michae1, Robert T. "Education and the Derived Demand for Children." In New Economic Approaches to Fertility, edited by T.W. Schultz. Proceedings of a conference sponsored by the National Bureau of Economic Research and the Population Council. Journal of Political Economy, 81, No. 2, Part II (March/Apri1 1973).

National Center for Health Statistics. Health, United States, 1983

DHHS Publication No. (PHS) 84-1232. Washington, D.C.: U.S. Government Printing Office, 1983. 
Rosenzweig, Mark R., and Schultz, T. Paul. "The Behavior of Mothers as Inputs to Child Health: The Determinants of Birth Weight, Gestation, and Rate of Fetal Growth." In Economic Aspects of Health, edited by Victor R. Fuchs. Chicago: University of Chicago Press for the National Bureau of Economic Research, 1982.

Rosenzweig, Mark R., and Schultz, T. Paul. "Consumer Demand and Household

Production: The Relationship Between Fertility and Child Mortality." American Economic Review, 73, No. 2 (May 1983a).

Rosenzweig, Mark R., and Schultz, T. Paul. "Estimating a Household Production Function: Heterogeneity, the Demand for Health Inputs, and their Effects on Birth Weight." Journal of Political Economy, 91 No. 5 (October 1983b).

Ryder, Norman B. "Time Series of Pill and IUD Use: United States, 19611970." Studies in Family Planning 3, No. 10 (October 1972). Sheridan, John F. "The Typical Perinatal Center." Clinics in Perinatology, 10, No. 1 (February 1983).

Sloan, Frank; Mitche11, Janet; and Cromwe11, Jerry. "Physician Participation in State Medicaid Programs." Journal of Human Resources, 13, Supplement (1978).

Williams, Anne D. "Fertility and Reproductive Loss." Ph.D. dissertation, University of Chicago, 1976.

Williams, Ronald L. "Outcome-Based Measurements of Medical Care Output:

The Case of Maternal and Infant Health." Ph.D. dissertation, University of California at Santa Barbara, 1974.

Willis, Robert. "A New Approach to the Economic Theory of Fertility Behavior." In New Economic Approaches to Fertility, edited by 


$$
R-5
$$

T.W. Schultz. Proceedings of a conference sponsored by the National Bureau of Economic Research and the Population Council. Journal of Political Economy, 81, No. 2, Part Il (March/April 1973). 


\section{APPENDIX}

\section{Data and Measurement of Variables}

The basic data set used here is the Area Resource File (ARF), a countybased data service, prepared by Applied Management Sciences, Inc., for the Bureau of Health Professions, U.S. Department of Health and Human Services. It incorporates information from different sources for the 3,077 counties of the United States. These counties can also be aggregated into larger geographic areas such as Standard Metropolitan Statistical Areas and States. The ARF is updated continuously to reflect the most recent data available. On the version of the ARF employed in this paper, socioeconomic characteristics are taken from the 1970 Census of Population. Socioeconomic characteristics from the 1980 Census of Population were not available on the ARF when we began this paper. Note, however, that we were able to add one key 1980 Census variable, the race-specific percentage of women aged 15 to 44 with family income less than 200 percent of the poverty level, to our version of the ARF. Note also that the race-specific number of women aged 15 to 44 in 1975 is available on our ARF tape. Note finally that schooling and employment levels of women ages 15 to 49 still are not available on the most recent version of the ARF.

The race-specific percentage of women aged 15 to 44 with family income less than 200 percent of the poverty level in 1980 (POV*) was computed by the Alan Guttmacher Institute (AGI, the technical assistance division of Planned Parenthood) from data in the 1980 Census of Population. It is highly correlated with the percentage of women aged 15 to 44 with family income less than 150 percent of the poverty level in 1980. The former 


$$
A-2
$$

variable performed slightly better in the regression analysis than the latter variable, both as an independent variable and as a denominator in measures of the availability of public programs for poor women. The results are not, however, sensitive to the poverty measure employed. Since poverty and family income are highly correlated, the latter is omitted from the regressions. In equations not shown in the Section III of the paper, race-specific median family income in 1969 projected to 1975 based on county trends in non-race specific per capita income was included as an independent variable. Its coefficient was not significant. We emphasize the poverty measure rather than median family income because the former pertains to women in childbearing ages. Note that regression results are not sensitive to the substitution of family income for poverty. The percentage of women aged 15 to 49 who had at least a high school education in 1970 (HSP*) and the percentage of women aged 15 to 49 employed in 1970 (EMP*) were taken from the ARF. The original source was the 1970 Census of Population, Women of Childbearing Age Tape.

The number of non-federal obstetricians/gynecologists in patient care in 1975 per thousand women aged 15 to 44 in 1975 (OBG) and the percentage of such physicians who are board certified (POBG) were taken from the ARF. The percentage of board-certified obstetricians/gynecologists was available for all non-federal physicians in this specialty as opposed to those in patient care. Attempts to include in the regressions such additional variables as the number of pediatricians in patient care (or the number of hospital-based pediatricians in patient care) per thousand women aged 15 to 44 and the percentage of board-certified pediatricians resulted in severe multicollinearity problems and were abandoned in the final specifications. 
The results presented in Section III are similar to those obtained with a physician measure defined as the sum of obstetricians/gynecologists and pediatricians per thousand women aged 15 to 44.

The three dichotomous variables that reflect the eligibility of lowincome women who are pregnant for the first time for Medicaid coverage of their prenatal care (MPA, MPU, and MPN) were obtained directly from Letty Wunglueck of the Health Care Financing Administration. The dichotomous variable pertaining to Medicaid financing of newborn care (MNEW) was taken from Davidson, Simon, and Connelly (1982). The state-specific average annual Medicaid payment per adult recipient in AFDC families in fiscal 1976 (MBEN) came from the Health Care Financing Administration (1979). Medicaid payments per adult recipient is employed rather than Medicaid payments per AFDC family or Medicaid payments per child recipient in AFDC families because prenatal care is received by women, and newborn care of ten is paid under the mother's Medicaid number.

In preliminary regressions we used an estimate of the county-specific percentage of poor women aged 15 to 44 who received AFDC payments in 1976 as a positive correlate of Medicaid availability. This variable had a positive and in some cases statistically significant effect on neonatal mortality. This may reflect the endogenous nature of the AFDC status of low-income women. In particular, the birth rate of poor women in states with generous AFDC programs is likely to be higher than in other states as is the percentage of such women on AFDC. Given a higher death rate of babies born to poor mothers than of those born to nonpoor mothers, one will observe a positive relationship between the neonatal death rate and the percentage of poor women on AFDC. Moreover, it is inappropriate to control 


$$
A-4
$$

for this effect by including the percentage of births to poor women as a regressor in the reduced form because the latter variable is endogenous. Note that the county-specific average monthly AFDC payment per recipient also was employed in preliminary regressions. This variable was not a significant predictor of neonatal mortality because it captures two effects that go in opposite directions. An expansion in AFDC payments augments the resources available to poor women but also encourages them to have more children. Both the AFDC eligibility measure and the AFDC benefit measure were excluded from the final set of regressions because the coefficients of the other variables were not sensitive to their omission.

Organized family planning availability is given by the number of organized family planning clinics in 1975 per thousand women aged 15 to 44 with family income less than 200 percent of the poverty level in 1975 (FPCLINP). These clinics are organized by hospitals, state and local health departments, Planned Parenthood, and other agencies such as M and I projects and CHCs. The numerator was obtained from a survey conducted by the Alan Guttmacher Institute and described by Forrest (1980). The denominator pertains to poor women because the clinics primarily service poor women and because the relevant public program is aimed at the poor. Since the numerator is not race-specific, neither is the denominator. The latter is obtained by applying the race-specific percentage of women aged 15 to 44 with family income less than 200 percent of the poverty level in 1980 to the race-specific number of all women aged 15 to 44 in 1975.

The extent of the maternal and infant care program and the community health center program is given by the sum of $M$ and $I$ projects and CHCs in 1976 per thousand women aged 15 to 44 with family income less than 200 per- 


$$
A-5
$$

cent of the poverty level in 1975 (BCHSP). The number of poor women serves as the denominator of this variable for the same reason that it serves as the denominator of the family planning measure. $M$ and $I$ projects and CHCs are aggregated in the numerator to reduce multicollinearity among the independent variables in the data set and because the coefficients of separate $M$ and I and CHC measures were not significantly different from each other in preliminary regressions. Moreover, although CHCs are not limited in terms of the type of medical care services provided or the age classes of low-income recipients, the centers were designed in part to service target populations with high infant mortality rates. In addition, all centers must provide prenatal and post partum care (Goldman and Grossman 1982). Finally, the Bureau of Community Health Services (BCHS, renamed the Bureau of Health Care Delivery and Assistance in 1982) of the U.S. Department of Health and Human Services has overall administrative responsibility for both $\mathrm{M}$ and $\mathrm{I}$ projects and $\mathrm{CHCs}$.

The number of $M$ and $I$ projects per county in 1976 was taken from the Bureau of Community Health Services ( $\bullet_{\bullet} d_{\bullet}$ ) and from unpublished information provided by Joann Gephart of the Bureau of Health Care Delivery and Assistance. The number of CHCs per county in 1976 was obtained from the BCHS Common Reporting Requirements data tape, which is described in detail by Goldman and Grossman $(1982,1983)$. The count of CHCs includes a sma11 number of migrant health centers and Appalachian health centers. Note that double counting of some organized family planning clinic providers occurs because certain $M$ and $I$ projects and CHCs provide these services and thus are included in the AGI data. This is not, however, a serious problem because the simple correlation coefficients between FPCLINP and BCHSP in 
the white and black samples (.17 and .13, respectively) are not large.

The state-specific percentage of eligible pregnant women served by WIC in 1980 (WIC) was taken from the Select Panel for the Promotion of Child Health (1981). Although this variable reflects use as well as availability, it is less closely related to use than a measure such as the number of users of BCHS projects per thousand poor women. This is because the users of BCHS projects receive a well defined set of services while the users of WIC do not.

Information on abortion providers is contained in annual surveys taken by the Alan Guttmacher Institute (for example, Forrest, Sullivan, and Tietze 1979; Henshaw et al. 1981).

Neonatal intensive care availability is measured by the sum of the state-specific number of hospitals with Level II, Level III, or Levels II and III neonatal intensive care units in 1979 per thousand women aged 15 to 44 in the state in $1975(\mathrm{NEOH})$. Hospitals that provide neonatal intensive care are generally divided into three levels based on the intensity of care each is equipped to deliver. Level I hospitals provide minimal or normal newborn care; Level II hospitals provide intermediate care and are sometimes called neonatal intermediate care hospitals; and Level III hospitals provide the most intensive care and are sometimes called neonatal intensive care hospitals (Budetti et al. 1981). Specific definitions of these three levels of neonatal care are contained in the recommendations of the Committee on Perinatal Health (1977), which were developed as guidelines for the regional development of perinatal health services. According to the committee, the function of Level I hospitals "... is to provide services primarily for uncomplicated maternity and newborn patients, and those with 
minor complications." Leve1 II hospitals can "...provide a full range of maternal and neonatal services for uncomplicated patients, for the majority of complicated obstetrical problems, and certain types of neonatal

111nesses." Level III hospitals "...must be able to provide the full range of resources and expertise required for the management of any complication of pregnancy or of the newborn." Level III hospitals are designed to be regional centers that accept referrals from other hospitals and coordinate and direct the transportation of referred patients.

As summarized by Budetti et al. (1981) and Sheridan (1983), many definitional problems arise in attempting to measure the number of hospitals with Level II or Level III neonatal intensive care units in the U.S. These difficulties are reflected in data contained in the American Hospital Association's (AHA) annual survey of hospitals. Until its 1979 survey, the AHA did not distinguish between Leve1 II and Level III hospitals, but it did distinguish between hospitals with neonatal intensive care units and hospitals with neonatal intermediate care units. From 1976 (the first year in which the AHA counted hospitals with neonatal intensive or intermediate care units) to 1979 , the number of hospitals with neonatal intensive care units declined (AHA 1977, 1979). Budetti et al. (1981) attribute this apparent reduction to problems encountered in the first years of reporting a new survey item and to definitional issues.

Given the above problems and the availability of level designations in the 1979 AHA survey, this survey was used as the primary data base to construct the neonatal intensive care measure employed in this paper. The AHA survey was supplemented, however, by the 1979 Guide to Referral Centers Providing Perinatal and Neonatal Care (Level III hospitals) prepared by 
Ross Planning Associates of Ross Laboratories and by Ross's 1982 Guide to Centers Proving Perinatal and Neonatal Special Care (Level II and Level III hospitals). A tape with all hospitals that reported a neonatal intensive care unit, a neonatal intermediate care unit, or both units was obtained from the AHA. If the hospital designated its unit as Level II or Level III it was included in our measure; if it designated its unit as Level $I$, it was excluded. Hospitals with a neonatal intensive care unit and a neonatal intermediate care unit were retained if at least one of the units was designated as Level II or III. Hospitals with missing level designations were retained and designated as Level III if they appeared in the 1979 Ross guide. Those with missing level designations were retained and designated as Level II if they appeared in the 1982 Ross guide (but not the 1979 guide) or if they appeared in neither guide but were designated as neonatal intensive care hospitals on the AHA tape and reported positive beds and patient days pertaining to this type of care.

Hospitals in the 1979 Ross guide but not on the AHA tape also were included in our variable. Hospitals in the 1982 Ross guide but not on the AHA tape were excluded because the criteria for inclusion in the 1982 guide were much more vague than the criteria for inclusion in the 1979 guide (Ross Planning Associates 1979, 1982), and some of the hospitals listed may be Level I facilities. In addition, certain hospitals in the 1982 guide may have opened their neonatal intensive care units in 1981 or 1980 . Finally, only 62 percent of the hospitals in the 1982 guide responded to a Ross survey on beds, admissions, patient days, staffing patterns, and equipment. On the other hand, over 95 percent of AHA member hospitals responded to the 1979 AHA survey which collected similar information. We 
were reluctant to include Ross Level II hospitals that were not on the AHA tape in our count because information on the measures just listed, which can be viewed as supporting evidence of the Level II designation, was missing for many of them. Note that all Ross Level III hospitals that were not on the AHA tape responded to the Ross survey in writing or by telephone.

The count of neonatal intensive care hospitals does not distinguish between Level II and Level III hospitals because of the definitional problems referred to above. The variable in the regressions pertains to the number of hospitals with neonatal intensive care units rather than to the number of neonatal intensive care units because Level III hospitals provide a full range of services, including those delivered by Level II hospitals, but are likely to report only one neonatal intensive care unit. The measure used here contains facilities defined as neonatal intermediate care hospitals by the AHA if their designations are Level II. No attempt was made to enter the number of Level I neonatal intensive care hospitals per thousand women aged 15 to 44 as a regressor because of potential multicollinearity between it and such regressors as the neonatal intensive care variable actually used, the number of abortion providers, and the number of obstetricians/gynecologists. We believe that our neonatal intensive care variable is the most relevant measure of the role of hospital availability in current birth outcomes in the U.S.

The lagged and current rate-specific neonatal mortality rates were computed from the ARF. Grossman and Jacobowitz (1981) argue that the overall lagged infant mortality rate (not race- and age-specific) is superior to the race- and age-specific measure if the overall rate was used to identify 
target populations with poor initial health levels. Results with the latter variable (not shown) are very similar to those contained in Section III.

\section{Extrapolations: Sources and Assumptions}

With two exceptions, the terminal values of the independent variables in the extrapolations are given by the race-specific weighted means in Table 2 of the paper. The exceptions pertain to the schooling and employment levels of women aged 15 to 49 since 1970 measures are used in the regressions. The race-specific percentages of women aged 15 to 49 with at least a high school education in 1977 (the terminal year) and in 1964 (the initial year) were taken from the Bureau of the Census (various years). The assumption was made that the race-specific ratio of the percentage of wome aged 15 to 49 with at least a high school education to the percentage of women aged 25 and over with at least a high school education in 1970 also applied to 1964 and 1977. Terminal and initial values of the race-specific percentage of women 15 to 49 employed were computed from the Bureau of Labor Statistics (1982).

The initial values of the Medicaid, $\mathrm{CHC}, \mathrm{M}$ and I, abortion, and WIC measures are set equal to zero. This is because the Medicaid and $\mathrm{CHC}$ programs were not enacted until 1965; there were few $M$ and I projects in operation until 1967 (Bureau of Community Health Services n.d.); the WIC program did not start until 1972; and no state reformed its abortion law until 1967. Although abortion was permitted to preserve a pregnant woman's life in 1964, the number of providers per thousand women aged 15 to 44 was ext remely small in that year. 
The initial value of the number of organized family planning clinics pertains to 1965. It was computed by applying the ratio of users per clinic in 1968, reported by Cutright and Jaffe (1977), to the number of users in 1965, also reported by Cutright and Jaffe. The number of hospitals with neonatal intensive care units in 1964 was estimated from data given by Sheridan (1983). He presents a time series of the number of neonatal intensive care hospitals based on a survey of Level II and Level III hospitals by Ross Planning Associates. Since the survey had only a 62 percent response rate, we multiplied his 1964 figure by the ratio of our 1979 estimate to his 1979 estimate.

The number of obstetricians/gynecologists in 1964 was obtained directly from Jean Robak of the American Medical Association. There are no estimates of the percentage of such physicians who were board certified in 1964 . Therefore, a 7.5 percentage point increase between 1964 and 1977 was assumed. The extrapolations are not sensitive to alternative assumptions concerning the behavior of this variable.

The initial value of the race-specific percentage of women aged 15 to 44 with family income less than 200 percent of the poverty level pertains to 1965. There are no actual figures for that year, but figures for 1970 are available in Cutright and Jaffee (1977). Estimates for 1965 were obtained as follows. Let $\mathrm{pw}_{70}$ and $\mathrm{pw}_{65}$ be the percentage of white women aged 15 to 44 with family income less than 200 percent of poverty in 1965 and 1970, respectively; let $\mathrm{pb}_{65}$ and $\mathrm{pb}_{70}$ be the corresponding percentages of black women in each year; let $\mathrm{yw}_{65}$ and $\mathrm{yw}_{70}$ be real median family income of whites in 1965 and 1970, respectively; and let $y_{65}$ and $y_{70}$ be real median family income of blacks in each year. Then $\mathrm{pw}_{65}$ is given by 


$$
\mathrm{pw}_{65}=\left(\mathrm{pw}_{70}\right)\left(\mathrm{yw}_{65} / \mathrm{yw} 70\right)^{\alpha} \text {, }
$$

and $\mathrm{pb}_{65}$ is given by

$$
\mathrm{pb}_{65}=\left(\mathrm{pb}_{70}\right)\left(\mathrm{yb}_{65} / \mathrm{yb}_{70}\right)^{\alpha \mathrm{b}} \text {. }
$$

Real race-specific median family income was taken from the Bureau of the Census (various years) and pertains to whites and nonwhites. The parameters $\alpha_{w}$ and $\alpha_{b}$ were taken from regressions of the natural logarithm of the race-specific percentage of women aged 15 to 44 with family income less than 200 percent of poverty on the natural logarithm of race-specific median family income in 1980. The regressions were estimated with the county data set employed in this paper. Based on these regressions, $\alpha_{w}$ was set equal to -1.1 , and $\alpha_{b}$ was set equal to -.4 .

\section{Appendix References}

American Hospital Association. Hospital Statistics. Chicago: American Hospital Association, 1977, 1979.

Budetti, Peter et al. "Costs and Effectiveness of Neonatal Intensive

Care." In The Implications of Cost-Effectiveness Analysis of Medical

Technology. Office of Technology Assessment, U.S. Congress. Washington, D.C.: U.S. Government Printing Office, 1981. Bureau of the Census. Statistical Abstract of the United States. Washington, D.C.: U.S. Government Printing Office, various years. Bureau of Community Health Services. "Maternity and Infant Care Projects Statistical Summary - Fiscal Year 1976." U.S. Department of Health, Education and Welfare, Public Health Service, n.d. Bureau of Labor Statistics. Labor Force Statistics Derived from the Current 
Population Survey: A Databook. Volume I, Bulletin 2096. U.S. Department of Labor, 1982.

Committee on Perinatal Health. Toward Improving the Outcome of Pregnancy: Recommendations for the Regional Development of Maternal and Perinatal Health Services. White Plains, New York: National Foundation of the March of Dimes, 1977.

Cutright, Phillips, and Jaffe, Frederick S. Impact of Family Planning Programs on Fertility: The U.S. Experience. New York: Praeger Publishers, 1977.

Davidson, Stephen M.; Simon, Marlene B.; and Connelly, John. "Interstate Variation in Medicald Coverage of Newborns: Report of Phase 1." American Academy of Pediatrics, Department of Health Systems, Research and Development Working Paper No. 8, May 1982.

Forrest, Jacqueline D. "Exploration of the Effects of Organized Family Planning Programs in the Unfted States on Adolescent Fertility." Final Report, Contract No. NO1-HD-82844 from the National Center for Child Health and Human Development to the Alan Guttmacher Institute, October 1980.

Forrest, Jacqueline D.; Sullivan, Ellen; and Tietze, Christopher. Abortion 1976-1977: Need and Service in the United States, Each State and Metropolitan Area. New York: Alan Guttmacher Institute, 1979. Goldman, Fred, and Grossman, Michael. "The Impact of Public Health Policy: The Case of Community Health Centers." National Bureau of Economic Research Working Paper No. 1020, November 1982. Goldman, Fred, and Grossman, Michael. "The Production and Cost of Ambulatory, Medical Care in Community Health Centers." In Volume IV 


$$
\text { A }-14
$$

of Advances in Health Economics and Health Services Research, edited by Richard M. Scheffler, and Louis F. Rossiter. Greenwich, Connecticut: JAI Press Inc., 1983.

Grossman, Michael, and Jacobowitz, Steven. "Variations in Infant

Mortality Rates Among Counties of the United States: The Roles of

Public Policies and Programs." Demography, 18, No. 4 (November 1981). Health Care Financing Administration. Data on the Medicaid Program:

$$
\text { Eligibility, Services, Expenditures. } 1979 \text { Edition. Baltimore, }
$$

Maryland: Health Care Financing Administration, 1979.

Henshaw, Stanley K. et al. Abortion 1977-1979: Need and Services in the United States, Each State and Metropolitan Area. New York:

Alan Guttmacher Institute, 1981 .

Ross Planning Associates of Ross Laboratories. 1982 Guide to Centers

Providing Perinatal and Neonatal Care. Columbus, Ohio: Ross

Laboratories, 1982 .

Ross Planning Associates of Ross Laboratories. 1979 Guide to Referral

Centers Providing Perinatal and Neonatal Care. Columbus, Ohio:

Ross Laboratories, 1979.

Select Panel for the Promotion of Child Health. Better Health for Our

Children: A National Strategy. U.S. Department of Health and Human Services, Publication No. 79-55071, 1981 .

Sheridan, John F. "The Typical Perinatal Center." Clinics in Perinatology, 10, No. 1 (February 1983). 